\title{
Embedded Place-Responsive Learning, Participatory Video and Scholastic Achievement in Northern Manitoba Adult Environmental Education
}

\author{
Jeffray Roy Stepaniuk \\ Natural Resources Management Technology Program, University College of the North, The Pas, Manitoba, Canada \\ Email: jstepaniuk@ucn.ca
}

How to cite this paper: Stepaniuk, J.R. (2019) Embedded Place-Responsive Learning, Participatory Video and Scholastic Achievement in Northern Manitoba Adult Environmental Education. Journal of $\mathrm{Hu}$ man Resource and Sustainability Studies, 7, 191-232.

https://doi.org/10.4236/jhrss.2019.72013

Received: February 22, 2019

Accepted: April 13, 2019

Published: April 16, 2019

Copyright $\odot 2019$ by author(s) and Scientific Research Publishing Inc. This work is licensed under the Creative Commons Attribution International License (CC BY 4.0).

http://creativecommons.org/licenses/by/4.0/

\begin{abstract}
Academic performance is a challenge confronting many postsecondary students in Northern Manitoba. As such, this study explores the role of situated (field-based) learning and participatory video in facilitating scholastic achievement relating to local freshwater availability and mindfulness. First-year students $(n=97)$ enrolled at the University College of the North in The Pas were randomly assigned to four adult education approaches containing identical subject matter. Student performance was assessed using outcomes of quantitative testing that focused on either foundational concepts or applied skills. Empirical data were examined using ordered multinomial logistic regression and explored cursorily in relation to unsolicited qualitative statements arising from in-stream participatory video and digitally-captured post-test interviews for each enrollee. Non-conventional lesson interaction inclusive of a modified participatory video approach significantly ( $p=0.003)$ increased quantitative test score means by $26 \%$, raised applied skill scores by one grade level $(12 \%)$ and significantly $(\mathrm{p}=0.07) \mathrm{im}$ proved concept understanding between five and 20\%. Despite benefits, northern self-declared Aboriginal students still had lower $(-11 \%)$ test scores on average. Importantly, there was less of a difference academically between non- and self-declared Aboriginal student test scores when situated learning and participatory video use were compared to didactic delivery alone. By identifying non-conventional strategies for improvement in environmental education, tertiary level institutions are presented another option for increasing academic performance ideally mitigating high attrition rates that continue to plague postsecondary education in Northern Manitoba; and for that matter, Canada.
\end{abstract}




\section{Keywords}

Participatory Video, Place-Responsive Learning, Situated Learning, Environmental Education, Stream Discharge Calculation, Postsecondary Education, Freshwater Sustainability, Adult Education, Remote Learning, University College of the North (UCN), Freshwater Monitoring, Manitoba

\section{Introduction}

Northern Manitoba's vision related to scholastic resolve is that every learner will pursue an education with a reflective sense of accomplishment and hope. Recognized as a priority are the educational needs of geographically isolated and culturally diverse communities consisting of First Nation Cree (Ininew/Inniniwak), Métis residents and newly arriving migrants. These mixed adult learning cohorts are habitually confronted by complicated and multifaceted difficulties. Critical to communal disappointment is academic under-preparation [1], a geography with extraordinary commuting distances, declining enrolments [2], intergenerational trauma [3] and inadequate tertiary-level research [4]. Disjointed technology [5] and incomprehensive credit transfer strategies [6] are omnipresent. There are also longstanding needs for contextual curative counseling [7] [8] and family housing in proximity to postsecondary infrastructures [9] [10].

Related specifically to Indigenous pre-tertiary accessibility are low secondary success rates for Aboriginal students that are half the national average [11] [12]. These same place-sensitive students are confronted by culturally-incongruous pedagogical approaches assimilative in nature and chronologically perceived as poorly designed and irrelevant to their lives [1] [13] [14] [15] [16]. Contributing to poor academic performance and retention is a specific social and political influence as families and communities still contend with a legacy of assimilative policies, as well as existing proximate challenges including high unemployment, poor health, sustenance insecurities and poverty [1] [13]. For instance, Lake St. Martin First Nation community members generate a median annual income of $\$ 1636$, a figure \$22,558 below other Manitobans per year [17].

Besides wellbeing and truncated postsecondary challenges, pristine environments across northern Manitoba are altered by widespread resource extraction and ecological fragmentation. To think sustainably about ecologies entered, critical analysis of occupied spaces must be negotiated. For instance, the indispensable value of freshwater is increasingly appreciated as northerners witness how lentic and lotic environments respond to precarious ways in which watersheds are being exploited. Hydro-electric development has had extreme adverse impacts across Manitoba, including changes in hydrology, flooding, erosion, concentrations of methylmercury, permafrost [18] [19] and unique concerns regarding human health [20].

Northern boreal alterations, in particular, have had dramatic implications for 
Indigenous livelihoods [21]. River diversions and hydro development have in some cases displaced entire communities [22] reflecting a history of colonizing neglect and rippling oppression on the part of provincial and federal governments [18] [23] [24]. Not only do northern Manitoba communities have limited opportunities to address disruption, they have little support when it comes to influentially preparing residents for alterations in local environs. Consequently, isolated northern communities are 90-times more likely to experience freshwater-related concerns than other Canadians [25]. Moreover, commensurate educational and environmental narratives do not receive the same attention as those confronting urban populations [26]. For example, acquiring a responsive education and getting a glass of water are no simple tasks in these remote communities and this is putting the welfare and health of resident souls at grave risk [27].

In response, northern freshwater management strategies have been forwarded by federal and provincial governments, including comprehensive standards and protocols utilizing multi-barrier approaches intended to reduce threats from anthropogenic actions [28]. Unfortunately, strategies are perceived inadequate, due in part to a lack of standards and confusion about participant roles and responsibilities [29], deference in funding [30], inadequate stakeholder consultation [31], limited access to knowledge and skills related to watershed and freshwater monitoring [32] and derisory training [33].

In appraising shortcomings, it is suggested future freshwater monitoring and decision-making, include "alternate forms of scientific literacy" grounded in cross-cultural expressions and local motivations [34] [35] [36]. Of great importance to these northern Indigenous communities is a place-sensitive scholarship generating awareness regarding local fluvial fluctuation [37]. Addressing uncertainty and associated challenges regarding change is desperate [38] and new educational initiatives clearly play a vital role in addressing contemporary facilitative concerns [39] [40]. As conventional instruction is experiencing criticisms that decontextualized knowledge transmission is making youth careless and ignorant in their surroundings, it is proposed place-ethical erudition must connect the lives of the young to ecology and the community [39].

Unfortunately, the absence of a comprehensive conceptual base for awareness and facilitating relevant understanding in northern societies exists [41]. Inspired research must present sustained connectivity to even seasonal freshwater-related employment [42] [43] enabling local opportunity for transformative change centering on shifts in underlying biases and personal affective freshwater sustaining assumptions. Moving from dependence on classroom-based approaches towards combinatory integrations of purposeful lesson deliveries [44] [45] presents as sensible in delivering local skill set competencies "just-in-time" for isolated and mixed learning populaces.

Despite the existence and urgent needs of this substantial northern adult student population, educational delivery remains "urbanized" [46] [47] [48] [49] representing a barrier to Indigenous students while contributing to high north- 
ern failure and drop-out rates [50] [51] [52]. Sadly, most post-secondary curricula in northern Canada are still expressed Euro-centrically and wanting of local metonym and place-conscious applicability. Basic training and the hopes of post-graduate placement are eclipsed by unsuitable theoretical and academic approaches, ill-translation of foreign metaphors, and a general lack of understanding regarding regional freshwater sustainability which undermines local agentic expression. Consequently, freshwater monitoring meant to reflect a northern priority relies on data typically generated via scholarship recipients and good weather visits calendared from discourses of the city in a distant south.

Curricular typologies reflecting vernacular origin and multi-sensory learning experiences for local practice need to go beyond southern Cartesian conception and traditional western cognitive classes as northern notions regarding scholarship are understood differently [53] [54]. As disinterest is reflected in poor Indigenous student attention and performance in northern postsecondary academia [55], conventional approaches must rethink delivery to small mixed and transient populations strengthening northern student confidence in an understanding of their environment [56].

Indeed, attrition rates in the Natural Resources Management Technology Program at the University College of the North are $>80 \%$ each year [57]. Institutional resources and alternative approaches to curricular design, delivery and evaluation are urgently needed in ways that will result in improved student interest, retention, infused affective environmental-consciousness and scholastic performance-better preparing these participants using regionally situated theories and mediating technologies [56] [58]. Historically, references [59] [60] [61] suggested similar alternative "spatial topoanalysis" and aesthetic ideologies to denote the immediate environment must be considered "a third teacher".

\subsection{Situated Learning Theory and Northern Place-Consciousness in Education}

Situated learning, first described as a theoretical model of instruction by [62] has likewise made a significant impact on contemporary educational theory and delivery [56] [63]. The model contends meaningful learning takes place if "embedded" in the physical and social context in which it is used. References [63] [64] [65] professed early that learning is viewed as a process of social co-construction while [66] postulated situated theory produces a model of instruction with real practical application. More recently [67] [68] found "problem-based" opportunities contextualize knowledge promoting the development of greater skills and confidence in ways that are self-directed and grounded in locale.

Essentially, situated theory addresses the gap between real world and in-class learning. With the support of an expert guide, the theory represents an apprenticeship where novices take on progressive responsibility until they are able to function independently [69]. Rather than being colonial in nature, knowledge 
and skill acquisition are described as "situational enculturation" or the adopting of values and learning heritage of a particular community [70]. Knowledge is perceived as translated ceremony and a reflection of community beliefs through time [71] [72]. Topics are socially integrated and discussed critically. At a basic level, situated theory emphasizes the idea that much of what is learned is specific to the situation in which it is learned [56] [73]. Participants use craft tools as practitioners to become cognitive apprentices in that discipline's geo-philosophy [74] all while place-conscious theory is translated into a responsive architectural model for an articulated teaching "method of place".

\subsection{Place-Consciousness and Participatory Video}

In transferring and advancing meaning from one context to another, [75] [76] acknowledged "participatory video" (PV) can play a central role in situated learning extension. Evolving from conventional participatory research [77] and wider debates about PV and its practice [78] [79] [80], new technology is perceived as operationally advantageous in northern adult education. Now documented to engage regional inequalities visually [75] [81] [82], PV is expected to provide a tone and perhaps standard of reflexivity for the University College of the North and its diverse student demography introducing methodological insight and a refreshing platform enabling temporal and spatial connections-perhaps fore-fronting innovative passages into local condition and contextualized knowledge.

\subsection{Northern Application of Participatory Video and Quantitative Consideration}

First developed in 1967 with the economically and politically marginalized Fogo Island fishing community [83], film was used to assist Newfoundlands' island-villagers in identifying common problems and in coming to terms with local barriers. Through 16-millimeter film, it became possible for isolated community members and resource-related decision makers to move cooperatively toward shared development goals [84]. Verisimilitude into the Fogo islanders' situation was gained for those who had never traveled to Newfoundland's "ground zero".

Guided collaboratively by Colin Lowe, Fred Earle and Donald Snowden, film was used to develop a collective community vision and strategy for Fogo's bleak economic renewal [85]. Snowden is credited as the first person to use film media in a team-based "kitchen-counter" approach and his design has since become one standard for participatory community development [86]. Identified as the "Fogo Process", ephemeral outcomes have resulted in improved government policy and action for small remote communities [76]. Snowden's films substantiated rural poverty did not necessarily stem from economic deprivation. Core implications included isolation, the inability to access information, an absence in confidence and a lack of organization [87]. Film essentially created the requisite awareness, self-confidence and video "product" for people-advocated change to 
occur [88]. Inspired internationally by Fogo's prototype, PV methods have since been modified by a wide diversity of community-based researchers and social activists in attempts to better serve agentic need [76] [89]. The accessibility of video and its new capability for generating awareness have resulted in PV telling many stories.

Theoretically, a core aspect is local participants are considered subject-matter experts (i.e., people who understand the complexity of their own situations) capable of defining and articulating the focus of their digital accounts including: action research as a means for involving users in their own study [90]; program monitoring [91]; institutional capacity building [92]; knowledge creation regarding issues confronting Aboriginal communities [93]; principles of experiential learning related to social and gender impact assessment [94] [95]; and program evaluation in First Nations communities [89] [96].

By definition, PV can be understood as a process whereby groups collaboratively explore and document issues they face when telling their story through digital capture [97]. Methodologically, it is an iterative procedure which values traditional knowledge [98], enabling participant factions to gain control over decisions impacting their lives [68] [99] [100]. Although "video-products" do not usually target large audiences, this method and product development methodology have been used effectively for environmental advocacy, policy lobbying, social learning and education among attendees [101].

Promoted by [76], participatory video opens communication to project recipients assisting development of participant-led ventures. With far-reaching and sustainable impact, PV production furthers research and development activity from inception to finish by providing the opportunity to learn from the experience itself sharing usefulness on regional insights [102]. Reference [103] used such a product as a qualitative support tool for rural development coining the phrase "embedded video for social change" referring to a contemporary strategy that recognizes a potential process for enhanced learning.

Not only is video capacity now recognized to document dynamic advance within paradigmatically-pluralistic participants, it demonstrates an ability to mobilize knowledge, chronicle the evolution of creativity, improve technical maturation and generate confidence in problem-solving experiential approaches [68] [89]. Participatory video has also helped to incorporate and synthesize Indigenous knowledge and scientific data relating to community-led research [104].

While important in its own right, contemporary video research tends to be "qualitative" in nature and although evangelized as innovative for decades [76] [105] [106], critical review indicates PV has yet to be evaluated as a scholastically-driving learning tool with a capacity to gauge academic achievement. Forwarding PV has yet to fulfill its promise; reference [107] has suggested the technology and its growth rate have creatively waned. Hence, the question remains: can PV and non-traditional adult lesson delivery work together in credible aca- 
demic ways? Reference [108] first addressed this question suggesting video recording techniques have been advocated "without" empirical evidence on scholastic efficacy. Remarkably, academic relevance of PV has yet to be verified using "quantitative" test score documentation in non-conventional erudition.

\subsection{The Need for Transforming Instructional Methods at University College of the North}

Since 1966, the University College of the North (UCN) [previously Keewatin Community College (KCC)] has provided adult educational programming for culturally diverse communities spread across a vast and unique landscape. The $325,000 \mathrm{~km}^{2}$ service area is distinct, setting the institution apart from other colleges and universities in Manitoba [57]. As the only postsecondary institute physically located in the region, an established network of two campuses and 12 regional centers-nine in First Nations communities and three in the larger towns-provide education and training to 2500 enrolled students. This region contains 27 First Nations communities, 34 Métis settlements and seven ethnically diverse urban centers (i.e., Churchill, FlinFlon, Swan River, Thompson, The Pas, Wabowden and Snow Lake). Contextually, it is important to distinguish the UCN's northern function and its 75,000 inhabitant base as distinct from the remaining three public universities in the south (i.e., Brandon University, University of Manitoba and University of Winnipeg).

As a public institution mandated to provide post-secondary education integrating college and university programming for a northern population, UCN has facilitated a breadth of post-secondary offerings since 2002 where paradigmatic shifts have reshaped a vocational technical college (KCC) into a combined college-university (UCN). This change in mandate reflects a regional and "perceived" shift from assimilation to accommodation with situated support for place-conscious paradigms. The 2016 UCN Act (C.C.S.M. c. U55) intention is to ensure inclusive development embracing Aboriginal ancestry and communities in the region. Supporting a cultural responsiveness that reinforces a northern Indigenous integrity with an increasing flux of ethnoculturally-diverse migrants-the intent is to grow synergistically from geo-contextual learning experiences that emerge.

In response to the many barriers that confront northern Indigenous students in this expanse, UCN has adopted the Kenanow model to ensure a new education system that builds a strong identity in students and a rooted sense of belonging that presents the roles and responsibilities of northern "family living" to the larger world [10]. Specific challenges the UCN now faces as an isolated northern educational institution include an extremely high dropout rate of northern Indigenous students and a recent influx of southern university graduates retro-actively "exploiting" diploma-level programming in the hopes of authentic employment promise.

Beyond this evolving migrant and student constituency, the geography of UCN's service area is rich in natural resources, freshwater and research potential 
but Indigenous communities in the region often feel negatively affected by large-scale resource and hydroelectric development [24]. Alteration and hydropower-associated changes in water levels and flooding in particular have had dramatic impacts on many Indigenous communities across northern Manitoba.

Fascinatingly, provincial land ceding has created a need for Aboriginal communities to be competent in science-based techniques, while at the same time creating opportunities for natural resource-accredited certifications, diplomas and degrees. An increased capacity in technical skills in the environmental sciences integrated with Indigenous traditional expression is now expected to provide UCN adult learners increasing roles in freshwater and environmental monitoring responding to industry-associated changes within the region. One pre-requisite realization, however, is a better understanding of water basins and stream flow so as to comprehend local flow variability. This is especially important since Manitoba's provincial economy and public directorate, established in 2003, is predicated on the wise use of freshwater.

Unfortunately, as water flow needs to be studied and an increased demand for competent technicians' surfaces, northern participant enrollment and associated graduation from the UCN Natural Resources Management Technology Program has deteriorated markedly [10]. According to University of Manitoba economist Richard Lobdell, UCN needs to develop academic strategies that overcome educational barriers specific to its region [109]. Likewise, as past Chancellor of UCN, Ovide Mercredi has argued northern students deserve an opportunity to succeed at university which could be facilitated by appropriate instructional methods, stating "my community is not unique in their thirst for education [but if necessary] the university can eat its standards so my people can eat' [110]. Clearly, there is a desperate need for diverse teaching methods that may be more effective than those currently used. Regional effectiveness can certainly be achieved by technical training that includes "non-traditional" lesson deliveries and legitimate peripheral participation using affordable mediating technologies and methodologies.

Subsequently, the intent of this research is to examine whether place-conscious lesson delivery and PV can improve academic performance by comparing scholastic impacts of a didactic classroom lecture to three "non-traditional" contextualized lesson deliveries. The latter includes the use of PV in a didactic lecture and a situated learning field exercise with and without the use of PV. It is anticipated situated learning theory and PV will facilitate improved scholastic advance. Cursory video exploration of unsolicited personal behavioral transformations towards freshwater sustainability were additionally expected to support adult learning for northern remote students at the University College of the North, broadly increasing affective awareness and conscious subjective expressions about the critical importance of freshwater conservation in Manitoba.

Significantly, spiraling trends in graduation at the UCN reflect similar declines in postsecondary enrollment in natural resources programming at other colleges and universities across North America [55]. Consequently, moving 
adult learner psyches' towards place-conscious considerations necessary for sustainable futures must capture academic possibilities for re-imagining and co-constructing affective mindfulness and new vernacular opportunities in relation to freshwater [111] [112]. Preservation is one of the most significant challenges facing this generation. Wise stewardship is critical ... it is up to all of us.

\section{Methods}

Following an action research methodology [113] all students were instructed in the calculation of stream discharge either passively in the classroom or in the river. Stream discharge is technically defined as the volume of water flowing through a given cross-section of a stream over a given period of time (usually expressed in cubic meters per second) requiring several measurements of depth and velocity to yield an average stream discharge calculation. In the field, velocity calculations were obtained by participants using the Price No. 622 Type AA Current Meter and metric conversion chart (equipment commonly used by federal and provincial water resources agencies) (Plate 1).

During a one-hour period in September 2008, research methods were presented to 348 newly registered students at the UCN. These students were enrolled in Nursing, Law Enforcement, Early Childhood Education, Dental Assisting, Business Administration, Kenanow Education and the Natural Resources Management Technology (NRMT) programs. Of these students, 257 (74\%) agreed to attend a 90-minute lecture on historic and contemporary issues related to northern provincial freshwater sustainability, development, diversion and flooding. Attending a second and subsequent 60-minute Participatory Video (PV) orientation activity, 213 (61\%) of these adults learned to use a Sony DSR-PD170 digital video camcorder (Plate 2). An optimistic and remaining 203 (58\%) participants were next randomly assigned to four different lesson types: 1) didactic or classroom instruction without PV [n=33]; 2) didactic instruction with PV [ $\mathrm{n}=56]$; 3) situated instruction without PV [n = 41]; and 4) situated instruction with PV [n=73].

Of these 203 students, 89 didactic adult learners (with and without PV) attended a third session and second 60-minute conventional classroom lecture on the calculation of stream discharge. Both "didactic" and "didactic plus PV" student groups were provided technical notes and an opportunity to create records related to stream velocity. The remaining 114 situated learners (with and without PV) received no classroom-based lecture nor opportunity to develop notes, but only a 15-minute on-site pre-exercise stream discharge demonstration for the calculation of stream flow. Both groups ("situated" and "situated plus PV") were provided the identical technical note set didactic learners had received related specifically to discharge calculation-following completion of the on-site exercise so that all four lesson approaches would, in effect, have the same preparation materials necessary for subsequent testing. Of the original 203 candidates, 158 persisting students partook in a five-hour place-responsive field experience 
intending to measure in-stream river flow.

Both didactic and situated group learners were expected to complete the stream-based exercise in groups of three to five students resulting in one stream flow calculation per group. Students using PV were instructed to record activity challenges in applying didactic or situated learning lessons providing a unique digitally-documented opportunity to voice and share experiences related to stream monitoring (Plate 3 ). All participants were provided the opportunity to watch the video after engaging in the field activity.

\section{Data Analyses}

A "mixed" strategy for data collection and analysis focused on "quantitative" test score findings but incorporated cursory qualitative student post-interview surveys as well. First, upon completion of the field activity, quantitative scholastic learning outcomes were assessed for 97 (61\%) of the 158 field candidates who chose to be "graded" using an examination that evaluated written concept knowledge and applied skills acquisition. The test contained 22 questions at 57 marks inclusive of: six multiple choice; 10 sentence completion; four short answer; one essay answer; and one multi-segmented mathematical calculation question. Questions were categorized into two groups: 1) those "Necessary for Understanding" (NFU)—(12 questions/23marks); and 2) those "Mandatory for Procedure" (MFP)—(10 questions/34marks). NFU questions referred to underlying theory and concepts whereas MFP questions referred to applied place-based stream technique and skill competencies. All test questions were initially tabled with input from surrounding communities, pre-research focus group dialogues, UCN program instructor insights, and UCN Elders Council recommendations prior "structural" and evaluative considerations.

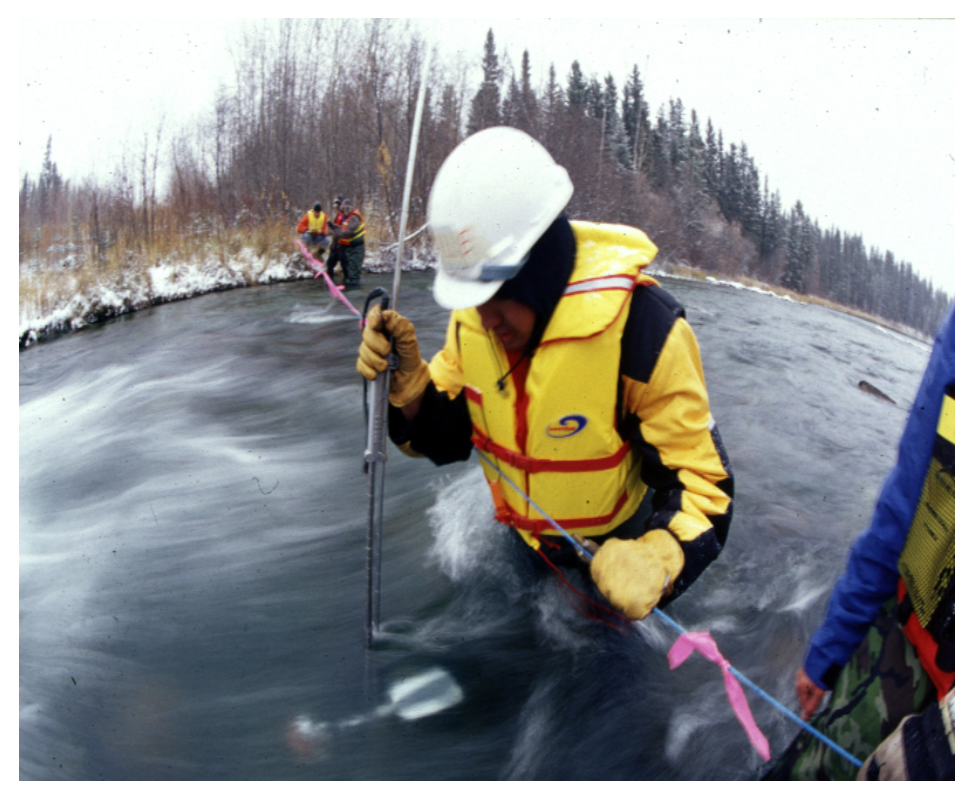

Plate 1. Students and equipment in action measuring in-stream water flow. 


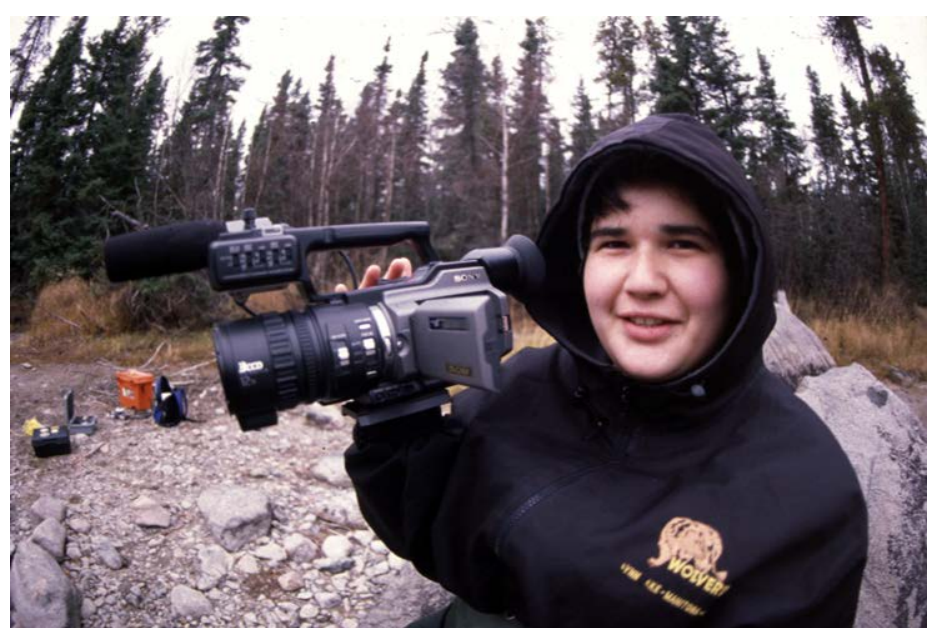

Plate 2. Student actively integrating situated Indigenous knowledge interviews with technological skills gained from participatory video workshop.

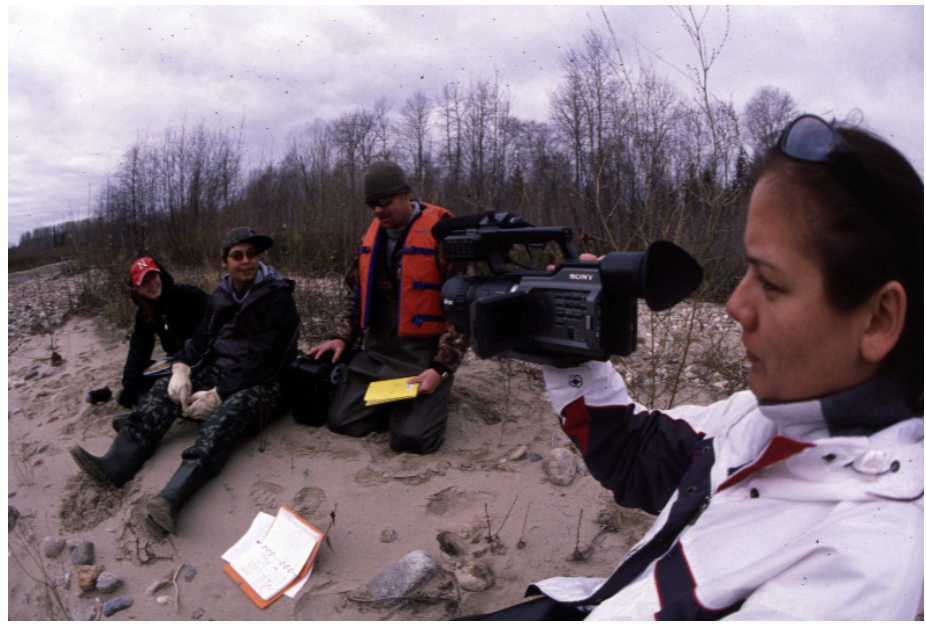

Plate 3. Participatory video field opportunities to voice experiential concepts.

To expand definition and comprehension of metric evolution, the instructional intent was to clarify and segregate the knowledge (NFU) and skills (MFP) "test-gap" by enabling new perceptions in learning and remote-based efforts to achieve training outcomes. Focus was on Indigenous participants who typically score well on field-based levels of navigation but "fail" scholastically-essentially unable to meet theoretical conceptualizations of scientific assessment placing themselves at greater risk of attrition. Subsequently, I make the case for separating essential technical training (or mandatory for procedure) metrics from theoretical foundations (or necessary for understanding) metrics. From this perspective, the MFP designation delineates specific field-level skills and equipment-use required to be independent and to manipulate tools and methods in often complex ways. This MFP separation highlights confidence and "competency of task" in remote Indigenous learners at their "academic" level to navigate confidently - a learning specific to the demands of local aptitude and an ability to contentedly re-check for accuracy while on-site. 
The NFU designation was in turn intended to identify "conceptual" gaps providing new strategies for developing and integrating facilitation of theoretical ideas with locally-derived MFP skills (Traditional Ecological Knowledge) advancing a new "foundation" for learning and adaptability to succeed. Without a strong "theoretical or NFU foundation", novice technicians would presumably have difficulty with what technical "scientific" training is intended to impart. It was subsequently perceived necessary to separate learning into these two components as NRMT UCN student evaluation tends to stumble here, particularly with regards to successful remote Indigenous student completion of technical preparation. It was hypothesized metric separation would focus insight towards success in fair assessment strategies for those perceived "scholastically-at-risk" but vernacularly-adept. No student group had access to test metrics prior testing. It took students 45 - 90 minutes to complete the resulting quantitative test which occurred two to three weeks following didactic lectures and situated in-stream exercises.

All Total, MFP and NFU test score separations were empirically examined. In addition to analysing absolute test scores, these data were ordered into three relative score categories and again re-analysed: 1 ) low score ( $0 \%-33 \%) ; 2)$ medium score (34\% - 66\%); and 3) high score (67\% - 100\%). Test scores were additionally categorized as pass $(>60 \%)$ or fail $(<60 \%)$ and re-analysed a third time-this according to NRMT UCN criteria for pass-fail grading. All scores were evaluated for subsample normality using Kolmogorov-Smirnov and Shapiro-Wilk tests. Equal variance was appraised using Levene's tests [114] [115]. As participant response variables were categorical, ordered logistic regression was used to explore, detect, describe and test predictive power of all naturally occurring sets of independent variables to: 1) assess the relative contribution of each; and 2) provide an indication for the adequacy of alternatively chosen models (i.e., sets of predictor variables) by assessing "goodness of fit" [116]. Variables included PV and lesson context (situated versus didactic) as well as gender, ethnicity (or learning modality), program type (NRMT versus other), theoretical (NFU) and practical (MFP) test scores.

Second, to cursorily supplement knowledge and skill acquisition test scores, I conducted "unstructured" open-ended video interviews using only "unsolicited" candidate response with each of the 97 remaining student participants. Interviews focused on what students had learned, what had facilitated learning and what had hindered learning. Interviews were digitally recorded, edited and catalogued using Final Cut Pro (V6). Interviews each lasted 20 - 30 minutes, generally proceeding until no new insights emerged. Categorized for what participants had in common as they experienced standing in a boreal stream, unsolicited and emerging "themes" were labeled, coded, surficially-examined for relationship with quantitative findings, considered for empirical quantification and archived in Final Cut Pro for repeated review and re-examination via group viewing and statistical consideration.

Examination was inductive, forming broad theme categories and reconfigur- 
ing each into new, narrow and revised constructs [117]. Inspection consisted of: 1) reviewing digital footage to obtain an overall place-responsive understanding; 2) identifying significant statements pertaining directly to the experience of how each participant experienced the stream-situated phenomenon; and 3) formulating open theme meanings clustering each into axial constructs common among participants [118] [119]. Criteria for status included: 1) the frequency of a theme's occurrence; 2) its inclusiveness and ease with which it related to other theme categories; and 3) the clarity of its implication as a potential "construct". A "construct" is the point at which theory is transformed into "measureable practice" and the explicit representation of an abstract phenomenon to be used in an emerging hierarchical place-based model expected to develop propositions related to outcomes of future "quantified qualitative" analyses of what each item on the test was supposed to measure ${ }^{1}$.

\section{Results}

\subsection{Quantitative Test Findings}

Although there was a great deal of variation in candidate test scores, student performance scholastically overall was low with respect to central tendency. Indeed, mean test scores for Total, MFP and NFU were 52\% (29.5/57), 49\% $(16.6 / 34)$ and $56 \%(12.9 / 23)$, respectively (Table 1$)$. Notably, preliminary descriptive statistical examination indicated Business Management and Law Enforcement program-level test score "means" did not meet the University College of the North's (UCN) minimum (60\%) academic grade requirement.

The impact of a number of independent variables on test scores was explored next. Of these, northern culture (preferably "learning modality") presented a strong role in academic performance. Total and MFP test scores for non-Aboriginal candidates were significantly $(\mathrm{p}<0.005)$ higher than for those who self-declared as Aboriginal (Table 2 and Table 3); although interestingly-not as significantly different for NFU scorings (Table 4). Tallies on the former group were higher on average by $41 \%$ ( 12 marks), $46 \%$ ( 8 marks) and $34 \%$ (4 marks) for Total, MFP and NFU scores respectively (Table 5).

When northern learning modality and question type were examined in detail, both Aboriginal and non-Aboriginal students did best successfully answering sentence completion (SC) and bullet answer (BA) question types whereas the

\footnotetext{
${ }^{1}$ As effective "non-traditional" approaches to environmental learning and evaluation in northern Manitoba remain ephemeral and abysmal failure rates have not changed in decades, there is relevance in exploring "experiential context" and the implications of an inductive northern student-centered learning model that will improve awareness, academic performance and evaluation. To prevent perpetuating a disorder in which traditional Indigenous cultural expressions are neither developed nor recognized, results from these quantitative test scores will be mixed with unsolicited quantified-qualitative (affective) student statements via exploratory factor analysis from an integrated but varied set of 27 chosen variables captured by participatory video. "Empiricalized" findings of unique meta-ethical learnings are expected to result in improved academic success when nurturing transformational learning, especially in the context of ongoing threats to both freshwater availability and preservation of traditional place-sensitive cultures in Manitoba.
} 
latter group did better in long answer (LA) and calculation (CA) type questions (Figure 1).

Gender also played an important role in determining academic performance. Total, MFP and NFU mean test sub-scores indicated males $(\mathrm{n}=24)$ tended to score higher than females $(\mathrm{n}=73)$; particularly for Total $(8 \%)$ and MFP $(14 \%)$ test score segments in this University College of the North student sample (Table 6). Outcomes of the ordered logistical regression indicated females did significantly poorer with respect to Total $(\mathrm{p}<0.009)$, MFP $(\mathrm{p}<0.028)$ and NFU ( $\mathrm{p}<0.005)$ test scorings (Tables $2-4$ ).

Table 1. Definition of and descriptive statistics for explanatory variables used in ordered logit analysis of total test score achievement.

\begin{tabular}{|c|c|c|c|c|c|}
\hline \multirow{2}{*}{ Label } & \multirow{2}{*}{ Description } & \multicolumn{2}{|c|}{$\begin{array}{l}\text { Categorical } \\
\text { Variables }\end{array}$} & \multicolumn{2}{|c|}{$\begin{array}{l}\text { Continuous } \\
\text { Variables }\end{array}$} \\
\hline & & Mean & S.E. & Mean & S.E. \\
\hline $\begin{array}{l}\text { Total Score } \\
\text { (Dependent) }\end{array}$ & $\begin{array}{c}1=\text { Low }(0 \% \text { to } 33 \%), 2=\text { Medium } \\
(34 \% \text { to } 66 \%), 3=\text { High }(66 \%>)\end{array}$ & & & 29.52 & 1.39 \\
\hline $\begin{array}{l}\text { MFP }^{1} \\
\text { (Dependent) }\end{array}$ & $\begin{array}{c}1=\text { Low }(0 \% \text { to } 33 \%), 2=\text { Medium } \\
(34 \% \text { to } 66 \%), 3=\operatorname{High}(66 \%>)\end{array}$ & & & 16.60 & 0.91 \\
\hline $\begin{array}{l}\mathrm{NFU}^{2} \\
\text { (Dependent) }\end{array}$ & $\begin{array}{c}1=\text { Low }(0 \% \text { to } 33 \%), 2=\text { Medium } \\
(34 \% \text { to } 66 \%), 3=\text { High }(66 \%>)\end{array}$ & & & 12.92 & 0.58 \\
\hline Aboriginal & $\begin{array}{l}1 \text { if respondent is an aboriginal; } \\
0 \text { otherwise }\end{array}$ & 0.45 & 0.05 & & \\
\hline Gender & 1 if respondent is a male; 0 otherwise & 0.25 & 0.04 & & \\
\hline $\mathrm{NRMT}^{3}$ & $\begin{array}{c}1 \text { if respondent is a student of Natural } \\
\text { Resource Management Technology; } 0 \\
\text { otherwise }\end{array}$ & 0.15 & 0.04 & & \\
\hline $\mathrm{PV}^{4}$ & $\begin{array}{c}1 \text { if respondent is under participatory } \\
\text { video }\left(\mathrm{SPV}^{11} \text { and } \mathrm{DPV}^{12}\right) \text { program; } 0 \\
\text { otherwise }\end{array}$ & 0.52 & 0.05 & & \\
\hline Aboriginal-PV & $\begin{array}{l}1 \text { if respondent is an aboriginal and } \\
\text { under participatory video (SPV and } \\
\text { DPV) program; } 0 \text { otherwise }\end{array}$ & 0.23 & 0.04 & & \\
\hline Non-Conventional & $\begin{array}{c}1 \text { if respondent is under } \\
\text { non-conventional (Situated, } \\
\text { SPV and DPV) program; } 0 \text { otherwise }\end{array}$ & 0.77 & 0.04 & & \\
\hline $\begin{array}{l}\text { Practical } \\
\left(\mathrm{ILS}^{5}, \mathrm{PD}^{6}, \mathrm{SD}^{7}\right)\end{array}$ & $\begin{array}{l}1 \text { if respondent is has practical skill } \\
\text { development; } 0 \text { otherwise }\end{array}$ & 0.59 & 0.05 & & \\
\hline $\begin{array}{l}\text { Theoretical } \\
\left(\mathrm{NE}^{8}, \mathrm{KS}^{9}, \mathrm{ED}^{10}\right)\end{array}$ & $\begin{array}{l}1 \text { if respondent is has improvement } \\
\text { learning system; } 0 \text { otherwise }\end{array}$ & 0.48 & 0.04 & & \\
\hline Gender-Aboriginal & $\begin{array}{l}1 \text { if respondent is an aboriginal male; } \\
0 \text { otherwise }\end{array}$ & 0.09 & 0.03 & & \\
\hline Gender-Situated & $\begin{array}{l}1 \text { if respondent is a male and under } \\
\text { Situated program; } 0 \text { otherwise }\end{array}$ & 0.09 & 0.03 & & \\
\hline
\end{tabular}

${ }^{1}$ MFP-Mandatory for Procedure; ${ }^{2} \mathrm{NFU}$-Necessary for Understanding; ${ }^{3} \mathrm{NRMT}-\mathrm{Natural}$ Resources Management Technology program; ${ }^{4} \mathrm{PV}$-Participatory Video; ${ }^{5} \mathrm{ILS}$-Improved Learning Strategy; ${ }^{6} \mathrm{PD}$-Personal Development; ${ }^{7}$ SD-Skills Development (environmental); ${ }^{8} \mathrm{NE}-\mathrm{New}$ Experience; ${ }^{9} \mathrm{KS}$-Knowledge Sharing; ${ }^{10} \mathrm{ED}$-Educational Development; ${ }^{11} \mathrm{SPV}$-Situated Lesson plus PV; ${ }^{12} \mathrm{DPV}$-Didactic Lesson plus PV. 
Table 2. Ordered Logit Analysis (Dependent variable Total Score) of total test score achievement.

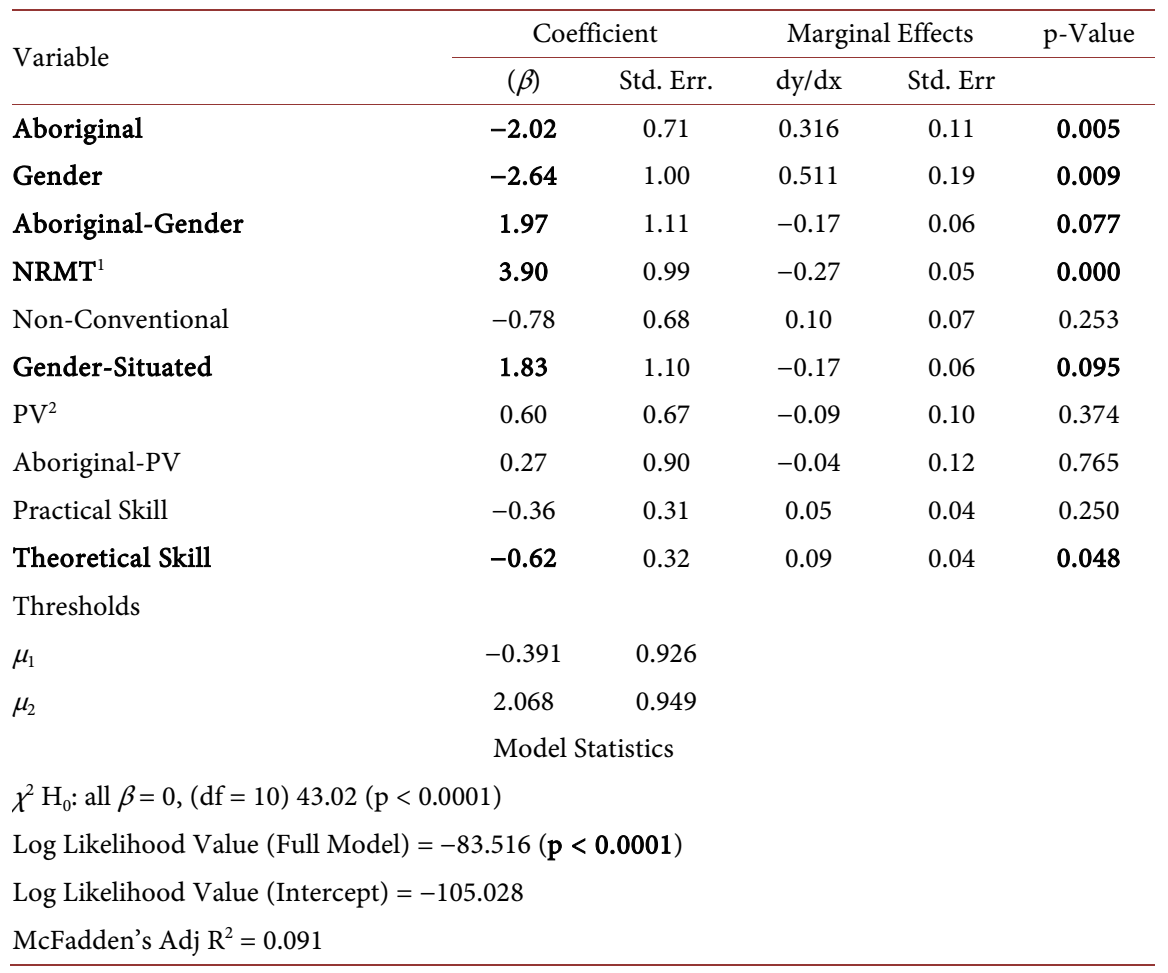

${ }^{1}$ Natural Resources Management Technology program; ${ }^{2}$ Participatory Video.

Table 3. Ordered Logit Analysis (Dependent variable MFP) of total test score achievement.

\begin{tabular}{|c|c|c|c|c|c|}
\hline \multirow{2}{*}{ Variable } & \multicolumn{2}{|c|}{ Coefficient } & \multicolumn{2}{|c|}{ Marginal Effects } & \multirow[t]{2}{*}{$\mathrm{p}$-Value } \\
\hline & $(\beta)$ & Std. Err. & $\mathrm{dy} / \mathrm{dx}$ & Std. Err & \\
\hline Aboriginal & -1.92 & 0.69 & 0.38 & 0.13 & 0.005 \\
\hline Gender & -2.02 & 0.92 & 0.45 & 0.19 & 0.028 \\
\hline Aboriginal-Gender & 1.78 & 1.02 & -0.23 & 0.08 & 0.082 \\
\hline $\mathrm{NRMT}^{1}$ & 2.91 & 0.85 & -0.34 & 0.06 & 0.001 \\
\hline Non-Conventional & -0.02 & 0.67 & 0.01 & 0.13 & 0.976 \\
\hline Gender-Situated & 1.27 & 0.100 & -0.19 & 0.11 & 0.203 \\
\hline $\mathrm{PV}^{2}$ & -0.03 & 0.63 & 0.01 & 0.13 & 0.961 \\
\hline Aboriginal-PV & 0.40 & 0.88 & -0.74 & 0.15 & 0.650 \\
\hline Practical Skill & -0.22 & 0.31 & 0.04 & 0.06 & 0.483 \\
\hline Theoretical Skill & -0.38 & 0.30 & 0.07 & 0.06 & 0.204 \\
\hline \multicolumn{6}{|l|}{ Thresholds } \\
\hline$\mu_{1}$ & 0.049 & 0.862 & & & \\
\hline \multirow[t]{2}{*}{$\mu_{2}$} & 1.844 & 0.883 & & & \\
\hline & Model & tistics & & & \\
\hline \multicolumn{6}{|c|}{$\chi^{2} \mathrm{H}_{0}:$ all $\beta=0,(\mathrm{df}=10) 33.19(\mathrm{p}<0.0001)$} \\
\hline \multicolumn{6}{|c|}{ Log Likelihood Value (Full Model) $=-89.958(\mathrm{p}<0.0001)$} \\
\hline \multicolumn{6}{|c|}{ Log Likelihood Value (Intercept) $=-106.555$} \\
\hline McFadden's Adj R ${ }^{2}=0.043$ & & & & & \\
\hline
\end{tabular}

${ }^{1}$ Natural Resources Management Technology program; ${ }^{2}$ Participatory Video. 
Table 4. Ordered Logit Analysis (Dependent variable NFU) of total test score achievement.

\begin{tabular}{|c|c|c|c|c|c|}
\hline \multirow{2}{*}{ Variable } & \multicolumn{2}{|c|}{ Coefficient } & \multicolumn{2}{|c|}{ Marginal Effects } & \multirow[t]{2}{*}{ p-Value } \\
\hline & $(\beta)$ & Std. Err. & $\mathrm{dy} / \mathrm{dx}$ & Std. Err & \\
\hline Aboriginal & -1.03 & 0.69 & 0.21 & 0.14 & 0.138 \\
\hline Gender & -2.72 & 0.98 & 0.58 & 0.17 & 0.005 \\
\hline Aboriginal-Gender & 1.19 & 1.12 & -0.18 & 0.13 & 0.288 \\
\hline NRMT $^{1}$ & 3.04 & 0.87 & -0.35 & 0.06 & 0.000 \\
\hline Non-Conventional & -1.65 & 0.70 & 0.26 & 0.09 & 0.018 \\
\hline Gender-Situated & 1.50 & 1.05 & -0.22 & 0.10 & 0.158 \\
\hline $\mathrm{PV}^{2}$ & 1.16 & 0.65 & -0.23 & 0.12 & 0.073 \\
\hline Aboriginal-PV & -0.71 & 0.92 & 0.15 & 0.21 & 0.435 \\
\hline Practical Skill & -0.05 & 0.30 & 0.01 & 0.06 & 0.965 \\
\hline Theoretical Skill & -0.74 & 0.32 & 0.15 & 0.06 & 0.021 \\
\hline \multicolumn{6}{|l|}{ Thresholds } \\
\hline$\mu_{1}$ & -0.001 & 0.881 & & & \\
\hline$\mu_{2}$ & 1.805 & 0.905 & & & \\
\hline \multicolumn{6}{|c|}{ Model Statistics } \\
\hline \multicolumn{6}{|c|}{$\chi^{2} \mathrm{H}_{0}:$ all $\beta=0,(\mathrm{df}=10) 37.00(\mathrm{p}<0.0001)$} \\
\hline \multicolumn{6}{|c|}{ Log Likelihood Value $($ Full Model $)=-87.995(\mathrm{p}<0.0001)$} \\
\hline \multicolumn{6}{|c|}{ Log Likelihood Value (Intercept) $=-106.495$} \\
\hline McFadden's Adj $R^{2}=0.061$ & & & & & \\
\hline
\end{tabular}

${ }^{1}$ Natural Resources Management Technology program; ${ }^{2}$ Participatory Video.

Table 5. Total, MFP and NFU test scores with respect to self-declared culture.

\begin{tabular}{|c|c|c|c|c|}
\hline Self-declared culture & & Total & MFP & NFU \\
\hline \multirow{4}{*}{ Non-Aboriginal } & Mean & $34.85\left(40.6^{*}\right)$ & $19.98\left(45.9^{*}\right)$ & $14.87\left(33.8^{\star}\right)$ \\
\hline & $\mathrm{n}$ & 53 & 53 & 53 \\
\hline & Standard Deviation & 12.367 & 8.233 & 4.840 \\
\hline & Std. Error of Mean & 1.699 & 1.131 & 0.665 \\
\hline \multirow{4}{*}{ Aboriginal } & Mean & 23.09 & 12.52 & 10.57 \\
\hline & $\mathrm{n}$ & 44 & 44 & 44 \\
\hline & Standard Deviation & 12.400 & 8.188 & 5.768 \\
\hline & Std. Error of Mean & 1.869 & 1.234 & 0.870 \\
\hline \multirow{4}{*}{ Total } & Mean & 29.52 & 16.60 & 12.92 \\
\hline & $\mathrm{n}$ & 97 & 97 & 97 \\
\hline & Standard Deviation & 13.650 & 8.982 & 5.676 \\
\hline & Std. Error of Mean & 1.386 & 0.912 & 0.576 \\
\hline
\end{tabular}

${ }^{*}$ Percentage difference (\%) higher test scores for non-Aboriginal participants in brackets. 
Table 6. Total, MFP and NFU test scores with respect to student gender.

\begin{tabular}{ccccc}
\hline Gender & & Total & MFP & NFU \\
\hline \multirow{3}{*}{ Female } & Mean & $\mathbf{2 8 . 8 9}$ & $\mathbf{1 5 . 9 9}$ & 12.90 \\
& $\mathrm{~N}$ & 73 & 73 & 73 \\
& Standard Deviation & 13.630 & 9.110 & 5.610 \\
& Std. Error of Mean & 1.595 & 1.066 & 0.657 \\
\multirow{3}{*}{ Male } & Mean & $\mathbf{3 1 . 4 2}\left(8.4 \%>^{*}\right)$ & $\mathbf{1 8 . 4 6}\left(14.3 \%>^{*}\right)$ & 12.96 \\
& N & 24 & 24 & 24 \\
& Standard Deviation & 13.828 & 8.495 & 5.996 \\
& Std. Error of Mean & 2.823 & 1.734 & 1.224 \\
& Mean & 29.52 & 16.60 & 12.92 \\
Total & N & 97 & 97 & 97 \\
& Standard Deviation & 13.650 & 8.982 & 5.676 \\
& Std. Error of Mean & 1.386 & 0.912 & 0.576 \\
\hline
\end{tabular}

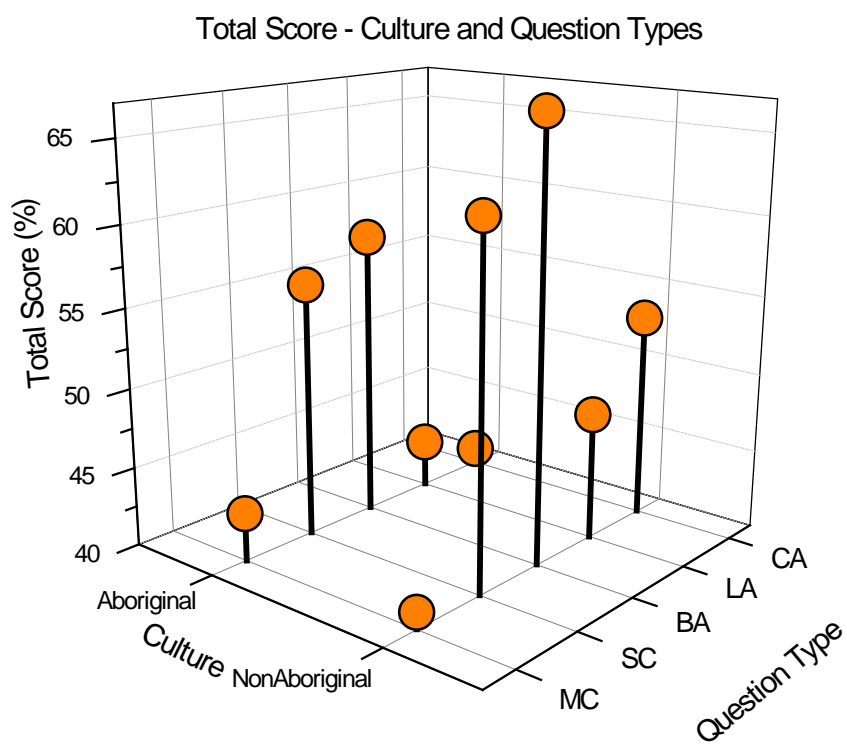

Figure 1. Total test score percent as related to culture and question type. MC-Multiple Choice; SC-Sentence Completion; BA-Bullet Answer; LA-Long Answer; and CA-Calculation.

The influence of gender on academic performance was also evaluated for types of questions. Of five different question types used to evaluate knowledge and skills acquisition, sampled males did substantially better in calculation (CA) type questions (Figure 2).

Academic performance also showed a significant interaction between learning modality and gender for Total $(\mathrm{p}<0.077)$ and MFP $(\mathrm{p}<0.082)$ test scores although not for NFU test scores (Tables 2-4). Mean MFP scores in particular showed there was much less difference in scholastic performance between non-Aboriginal men and women (9\%) than for Aboriginal men and women 
(12\%) (Table 7).

Student ability to score higher also varied according to sampled program types. To accommodate statistical requirement, non-NRMT programs were combined to increase sample size and accommodate parametric restriction. Comparisons chosen were made between Natural Resources Management Technology (NRMT) and "other" (non-NRMT) programs. Typically, students who enrolled in a natural resource (NRMT) related discipline had substantially higher academic test scores than those in "other" (non-NRMT) programs with respect to Total score ( $\mathrm{p}<0.000)$, MFP ( $\mathrm{p}<0.001)$ and NFU ( $<0.000)$ (Tables 2 -4). Mean Total, MFP and NFU test scores were $49 \%, 59 \%$ and $35 \%$ greater for students enrolled in the NRMT program (Table 8).

The impact of situated (place-responsive) non-conventional learning deliveries on academic performance was also assessed. Somewhat expectedly, test scores for NFU style questions were significantly higher $(\mathrm{p}=0.018)$ for students in didactic classes compared to those in non-conventional lectures (i.e., situated, situated plus PV, and didactic plus PV) (Table 4). Examined in detail, students had $21 \%$ higher grades, perhaps showing conceptual focus emphasized in the NFU test questions was better suited to a classroom style of learning (Table 9). Conversely, mean MFP test scores indicated only minor improvement for those who participated in non-conventional classes $(0.8 \%$, Table 9$)$ but significantly more so with self-declared Aboriginal participants (12\%, Table 10).

Mean Total, MFP and NFU test score comparisons additionally indicate a significant interaction $(\mathrm{p}=0.095)$ between males $(24 \%, 30 \%$ and $15 \%$ respectively) and females when exposed to non-conventional lesson delivery (Table 11). Remarkably, both genders seemed to do rather poorly scholastically when theory and learning were delivered conventionally (i.e., didactically) and not applied in an engaged situated setting.

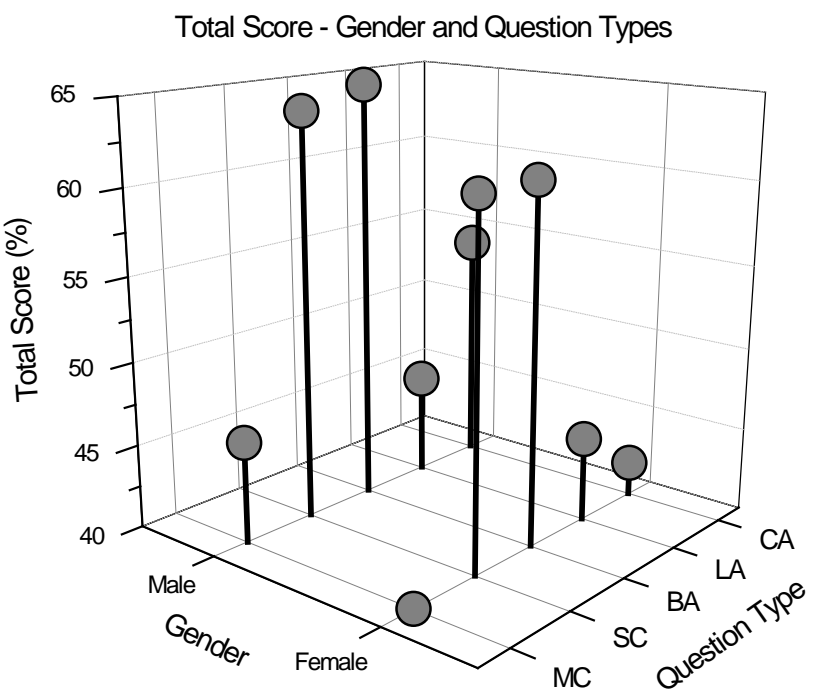

Figure 2. Total test score percent as related to gender and question type. MC-Multiple Choice; SC-Sentence Completion; BA-Bullet Answer; LA-Long Answer; and CA-Calculation. 
Table 7. Total, MFP and NFU test scores with respect to student culture and gender.

\begin{tabular}{lcccc}
\hline \multicolumn{5}{c}{ Total test score } \\
\hline Male & Aboriginal & Standard Error & Non-Aboriginal & Standard Error \\
Female & 23.89 & 3.49 & 35.93 & 3.59 \\
\% difference & 22.89 & 2.19 & 34.42 & 1.92 \\
\hline & $(4.28 \%)$ & & $(4.28 \%)$ & \\
\hline & & MFP & & 2.24 \\
\hline Male & Aboriginal & Standard Error & Non-Aboriginal & Standard Error \\
Female & 13.78 & 1.98 & 21.27 & 1.32 \\
\% difference & 12.2 & 1.47 & 19.47 & \\
\hline & $(12.2 \%)$ & & $(8.84 \%)$ & 1.53 \\
& & NFU & & 0.72 \\
\hline Male & Aboriginal & Standard Error & Non-Aboriginal & Standard Error \\
Female & 10.11 & 1.75 & 14.67 & 14.95 \\
\hline & 10.69 & 1.01 & & \\
\hline
\end{tabular}

Table 8. Total, MFP and NFU test scores with respect to program choice

\begin{tabular}{|c|c|c|c|c|}
\hline & Program Type & Total & MFP & NFU \\
\hline \multirow{4}{*}{ Non-Nl } & Mean & 26.82 & 14.70 & 12.12 \\
\hline & $\mathrm{N}$ & 82 & 82 & 82 \\
\hline & Standard Deviation & 12.826 & 8.234 & 5.716 \\
\hline & Std. Error of Mean & 1.416 & 0.909 & 0.631 \\
\hline \multirow{5}{*}{ NRMT } & Mean & 44.27 & 27.00 & 17.27 \\
\hline & *\% difference (NRMT \& non-NRMT) & $(49.1 \% *)$ & $\left(58.9 \%{ }^{\star}\right)$ & $(35.1 \% *)$ \\
\hline & $\mathrm{N}$ & 15 & 15 & 15 \\
\hline & Standard Deviation & 7.086 & 4.884 & 2.815 \\
\hline & Std. Error of Mean & 1.830 & 1.261 & 0.727 \\
\hline \multirow{4}{*}{ Total } & Mean & 29.52 & 16.60 & 12.92 \\
\hline & $\mathrm{N}$ & 97 & 97 & 97 \\
\hline & Standard Deviation & 13.650 & 8.982 & 5.676 \\
\hline & Std. Error of Mean & 1.386 & 0.912 & 0.576 \\
\hline
\end{tabular}

Table 9. Total, MFP and NFU test scores with respect to Lesson type.

\begin{tabular}{ccccc}
\hline & Total Score & MFP & NFU \\
\hline Mean (\% diff. increase $\left.{ }^{*}\right)$ & 31.68 & 16.50 & $15.18\left(21.4 \%^{*}\right)$ \\
Didactic & $\mathrm{N}$ & 22 & 22 & 22 \\
& Standard Deviation & 9.877 & 7.183 & 3.936 \\
& Standard Error of Mean & 2.106 & 1.531 & 0.839 \\
\hline
\end{tabular}




\section{Continued}

\begin{tabular}{ccccc}
\hline \multirow{4}{*}{ Non-Conventional } & Mean & 28.88 & 16.63 & 12.25 \\
& N & 75 & 75 & 75 \\
& Standard Deviation & 14.569 & 9.488 & 5.953 \\
& Standard Error of Mean & 1.682 & 1.096 & 0.687 \\
& Mean & 29.52 & 16.60 & 12.92 \\
Total & N & 97 & 97 & 97 \\
& Standard Deviation & 13.650 & 8.982 & 5.676 \\
& Standard Error of Mean & 1.386 & 0.912 & 0.576 \\
\hline
\end{tabular}

Table 10. Total, MFP and NFU test scores with respect to Lesson type as affected by culture.

\begin{tabular}{|c|c|c|c|c|}
\hline \multicolumn{5}{|c|}{ Total Score } \\
\hline & Non-conventional & Standard Error & Didactic & Standard Error \\
\hline Aboriginal & 22.38 & 2.33 & 25.50 & 2.17 \\
\hline Non-Aboriginal & 34.27 & 2.06 & 36.83 & 2.65 \\
\hline \multicolumn{5}{|c|}{ MFP } \\
\hline & Non-conventional & Standard Error & Didactic & Standard Error \\
\hline Aboriginal & $12.85\left(12 \% \uparrow^{\star}\right)$ & 1.51 & 11.40 & 1.62 \\
\hline Non-Aboriginal & 19.76 & 1.38 & 20.75 & 1.67 \\
\hline \multicolumn{5}{|c|}{ NFU } \\
\hline & Non-conventional & Standard Error & Didactic & Standard Error \\
\hline Aboriginal & 9.53 & 1.01 & 14.10 & 1.18 \\
\hline Non-Aboriginal & 14.51 & 0.79 & 16.08 & 1.15 \\
\hline
\end{tabular}

Table 11. Mean test score interaction between gender and lesson delivery.

\begin{tabular}{|c|c|c|c|c|}
\hline \multicolumn{5}{|c|}{ Total Score } \\
\hline & Situated & Standard error & Didactic & Standard error \\
\hline Male & $33.57\left(24.4 \% \uparrow^{\star}\right)$ & 5.59 & 30.53 & 3.34 \\
\hline Female & 26.28 & 3.87 & 29.75 & 1.70 \\
\hline \multicolumn{5}{|c|}{ MFP } \\
\hline & Situated & Standard error & Didactic & Standard error \\
\hline Male & $20.86\left(30.2 \% \uparrow^{\star}\right)$ & 3.33 & 17.47 & 2.04 \\
\hline Female & 15.39 & 2.44 & 16.18 & 1.18 \\
\hline \multicolumn{5}{|c|}{ NFU } \\
\hline & Situated & Standard error & Didactic & Standard error \\
\hline Male & $12.71(15.4 \% \uparrow)$ & 2.45 & 13.06 & 1.45 \\
\hline Female & 10.89 & 1.52 & 13.56 & 0.70 \\
\hline
\end{tabular}


The influence of facilitating knowledge and skill delivery were next compared among lesson types and question types. Sampled students in didactic classes generated higher Total test score percentages for sentence completion (SC), bullet answer (BA) and multiple-choice (MC) question types, whereas those in "situated" and "situated plus PV" classes produced improved long answer (LA) and calculation (CA) question scores-questions that required learning specific to the demands of on-site technical aptitude and the ability to re-check for accuracy of fact while in-situ (Figure 3). Reading, document use and numeracy were the focus as these skills are most often cited by instructors as stumbling blocks to successful completion of technical training as isolated and northern modality learners must deal with a staggering amount of information provided in a variety of formats within short periods of time.

The relative influence of participatory video (PV) as a mediating technology was statistically of less significance with this mixed UCN student group, at least as revealed by ordered logistic regression analysis for Total and MFP test scores (Table 2 and Table 3 ). Conversely, PV had a surprisingly significant positive ( $\mathrm{p}$ $=0.073$ ) influential effect on NFU test scores (Table 4).

Remarkably, Aboriginal students exhibited greater Total and MFP test scores using participatory video (Table 12). Additionally, and although not shown to be statistically significant with this sample, there was less of a difference between self-declared Aboriginal and non-Aboriginal mean Total and MFP test scores when PV was used (26\% for Total score and $42 \%$ for MFP score), in part perhaps because Aboriginal students were likely doing better with the use of participatory video and being presented an "opportunity" to express (and present) place conscious vernacular ability (Table 12). In sum, participatory video played a notable role with respect to northern learning modality. Non-Aboriginal students in PV classes attained lower Total, MFP and NFU test scores than those in non-PV related (i.e., situated, didactic) lecture deliveries.

Interestingly, female students using participatory video tended to score higher than their male counterparts with respect to Total (4\%), MFP (3\%) and NFU (6\%) mean test scores, which may be socio-culturally important since females in this sample typically performed less well than males academically (Table 13).

A profile plot for the interaction between program and participatory video (PV) indicated using PV resulted in higher Total test scores (19\%) for NRMT students but was not so beneficial (0.95\%) for non-NRMT program students (Figure 4). The difference between "NRMT plus PV" and "non-NRMT plus PV" students was an astounding $41 \%$, suggesting NRMT students in this UCN sample utilized PV most effectively with respect to Total test score and academic achievement. The difference between Total scores for students who used video and did not use video in the "situated" class deliveries also showed an important empirical difference (Figure 5). The estimated increase in test score between students who used video and those who did not was $17 \%$. Interestingly, there was also a 7\% increase in Total test scores in didactic delivery participant scores. 
Also apparent were test score findings indicating an important difference in NFU results with respect to the situated place-sensitive and non-conventional class deliveries between those who used participatory video and those who did not. Students in the situated exercises benefited from the use of video and acquired higher NFU test scores (Figure 6). Alternatively, students in traditional didactic lectures who used video generated lesser NFU scores; an interaction implying the effects of participatory video usage may vary depending on the lesson type. Students in the situated class who used video performed significantly better than those who did not use video ( $\mathrm{p}$-value $=0.003$ ) and obtained scores higher by approximately 26 points on the NFU segment of the examination. In contrast, students participating in the didactic class who used video performed less well (-9.8 points).

Table 12. Mean test score as an interaction between culture and participatory video.

\begin{tabular}{|c|c|c|c|c|}
\hline \multicolumn{5}{|c|}{ Total Score } \\
\hline & PV & Std. error & Non-PV & Std. error \\
\hline Aboriginal & $24.73\left(27.6 \%{ }^{\star}\right.$ dif. $)$ & 2.46 & $21.45(53.9 \% *$ dif. $)$ & 2.83 \\
\hline Non-Aboriginal & 32.64 & 2.81 & 37.32 & 1.69 \\
\hline \multicolumn{5}{|c|}{ MFP } \\
\hline & PV & Std. error & Non-PV & Std. error \\
\hline Aboriginal & $14.18(25.3 \% *$ dif. $)$ & 1.73 & $10.86(67.3 \% *$ dif. $)$ & 1.72 \\
\hline Non-Aboriginal & 18.29 & 1.86 & 21.88 & 1.10 \\
\hline \multicolumn{5}{|c|}{ NFU } \\
\hline & PV & ndard error & Non-PV & Standard error \\
\hline Aboriginal & 10.55 & 1.10 & 10.59 & 1.37 \\
\hline Non-Aboriginal & 14.36 & 1.07 & 15.44 & 0.74 \\
\hline
\end{tabular}

Table 13. Mean test score interaction between gender and participatory video.

\begin{tabular}{|c|c|c|c|c|}
\hline \multicolumn{5}{|c|}{ Total Score } \\
\hline & PV & Std. error & Non-PV & Standard error \\
\hline Male & 28.22 & 5.79 & 33.33 & 2.95 \\
\hline Female & 29.37 (3.99\%*^diff.) & 2.08 & 28.28 & 2.51 \\
\hline \multicolumn{5}{|c|}{ MFP } \\
\hline & PV & Std. error & Non-PV & Standard error \\
\hline Male & 16.11 & 3.61 & 19.87 & 1.75 \\
\hline Female & $16.56(2.85 \% * \uparrow$ diff. $)$ & 1.41 & 15.25 & 1.64 \\
\hline \multicolumn{5}{|c|}{ NFU } \\
\hline & PV & Std. error & Non-PV & Standard error \\
\hline Male & 12.11 & 2.44 & 13.47 & 1.36 \\
\hline Female & 12.80 (5.54\%* $\uparrow$ diff. $)$ & 0.80 & 13.03 & 1.04 \\
\hline
\end{tabular}




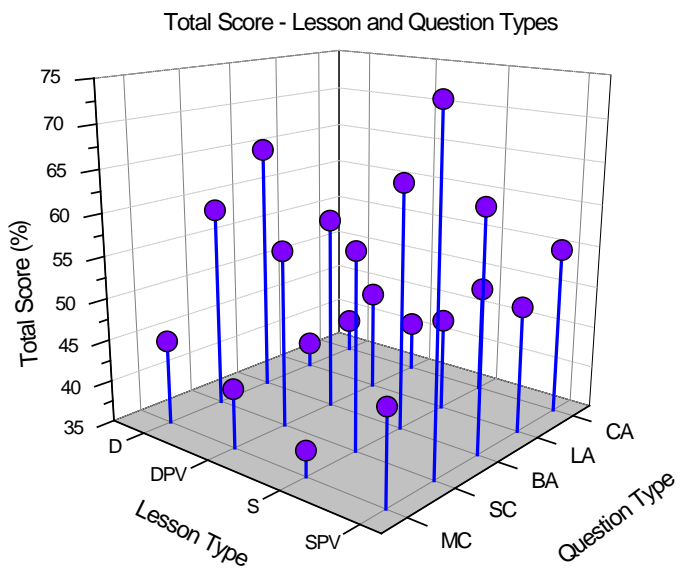

Figure 3. Total test score percent related to lesson type and question type. D-didactic; DPV-didactic + PV; S-situated; SPV-situated + PV; MC-Multiple Choice; SC-Sentence Completion; BA-Bullet Answer; LA-Long Answer; and CA-Calculation.

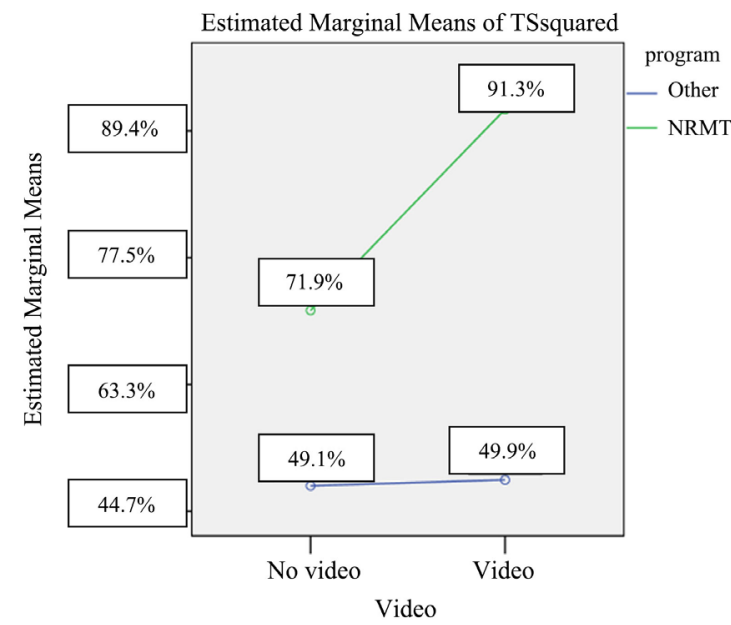

Figure 4. Profile interaction between participatory video and program. To convert TS-squared to percent, take the square-root.

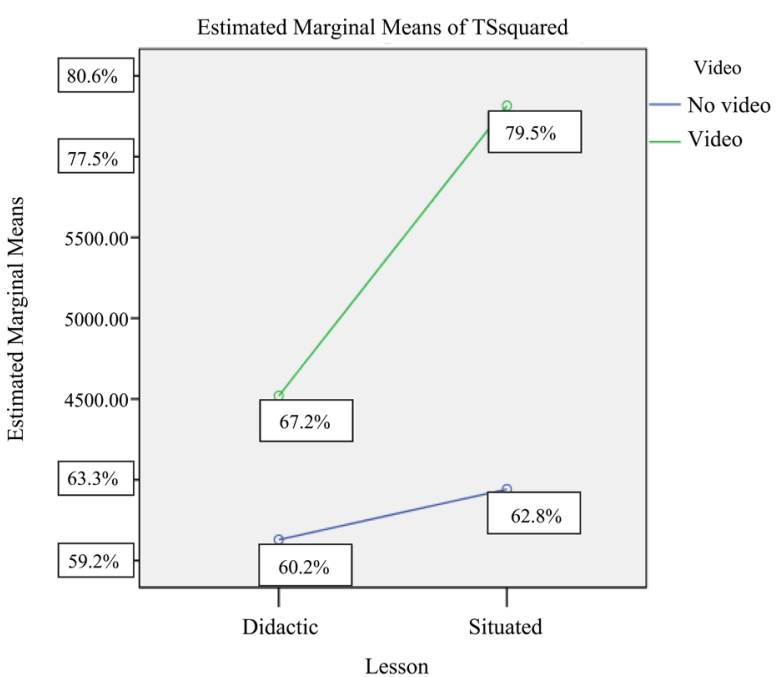

Figure 5. Profile interaction between participatory video and lesson type. 


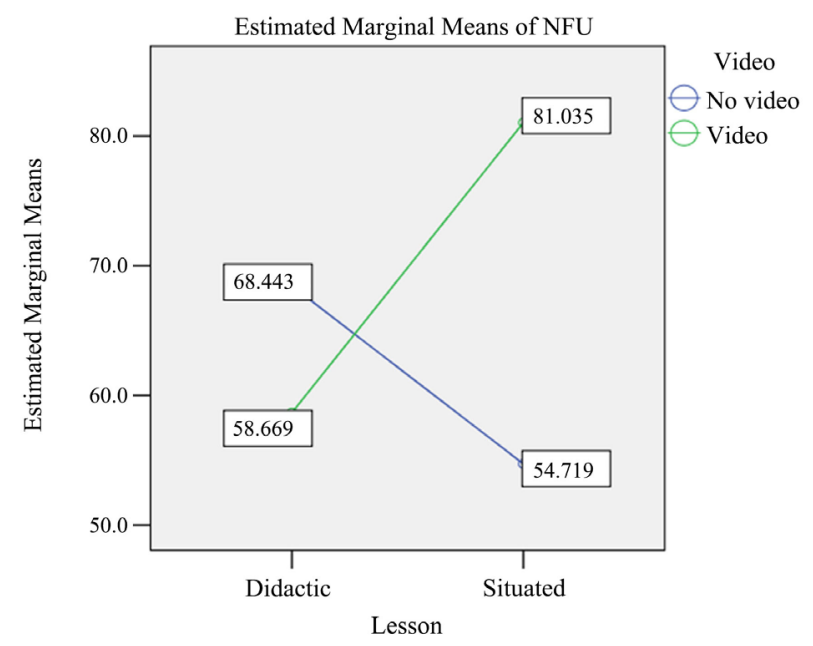

Figure 6. Profile plot for the interaction between lesson and video.

\subsection{Cursorily Related Qualitative Findings}

While not apparent in quantitative test score evaluation, students interviewed about their experiences often indicated they had found "non-conventional" approaches to lesson delivery to be of great value. From unsolicited interview response, different themes were cursorily identified that casually spoke to the nature of scholastic benefits providing direction for further integrated post-study design phases to be examined ${ }^{1}$. These cursorily-explored affective and unsolicited themes included being situated (i.e., "liminality" as a place of no words between here and there) [37] and bringing polyvocality [120], generating a positive incomprehensiveness in-situ, developing technology-related skills, acquiring place-responsive knowledge and experiencing personal overt behavioral change (i.e., Eureka, aha, and quale).

Contextually, didactically-lectured students found it difficult to pay attention and apply details of the stream water monitoring technique following the traditional lesson sessions but not while coached "on-the-land" and having to manipulate technical equipment in complex ways. In the voice of one nursing student, "I realized a strategy that is from situation to lecture setting rather than the reverse, so I will now try to do more in clinical settings as this was an easier way to learn". Students in non-conventional environments indicated "there was an increased attention-both voluntary and demanded by being there"; and "being in the cold and snow was peaceful - it was a less strict environment".

The stream discharge calculation exercise also incorporated an element of "situated collaboration" foundational to be reflexive and perform successfully on the job; defined here as dialoguing responsively to achieve success by sharing knowledge and saliently building consensus within the small student working groups (Plate 4). Student cohort-generated statements included "groups provided a reinforcement of concepts"; and "as a group there was completion [of the exercise]-most likely not possible by myself". Clearly a disappointing in-situ performance is not "all" due to limited technical skills ability but numer- 
ous cooperatively contributing factors that lead to a purer understanding about what influences make tasks more or less difficult.

Engaged participation in an experiential learning setting also indicated an increased situational "awareness" among a majority percentage (93\%) of students; a rapid socio-ecological change generating an ethical imperative to be responsive. By definition, "awareness" was defined as the ability to perceive, or be conscious of events, objects or patterns culminating in situated "mindfulness". Unsolicited statements ranged from being cognizant of boreal freshwater to new understandings of self and group dynamics. One student mentioned " $I$ am examining the concept of a watershed differently - the exercise has opened my eyes to humanity's cost and use of nature". Other students indicated "it was difficult to step back-I am more accepting of others perspectives" and "I believe I am a better person with an improved and more focused understanding".

Occasionally, place-based awareness seemed focused on an internal state (a visceral feeling) whereby participating "in the stream" generated an awareness enabling students to experience "Eureka!" or transformative conscious subjective ideas (CSE) about "their" experiences (i.e., aha moments, qualia). For example, some expressed feeling "less hope, and less in-control knowing this information". Others indicated "a cultural and community holistic connectivity" even though they had lived in northern Manitoba all their lives without having ever crossed a flowing stream, stating they were "terrified and in awe at the same time-I won't forget it'.

Other unsolicited responses indicated non-conventional delivery procedures may play a strong role in enhancing student knowledge and skill development. Students specified "these skills will certainly improve my chances for career development"; and " $P$ ve realized a confidence in communication, a decreased anxiety and a reduced stereotype casting". These latter statements effectively reflect the UCN mission and recent strategy $[10]^{1}$.

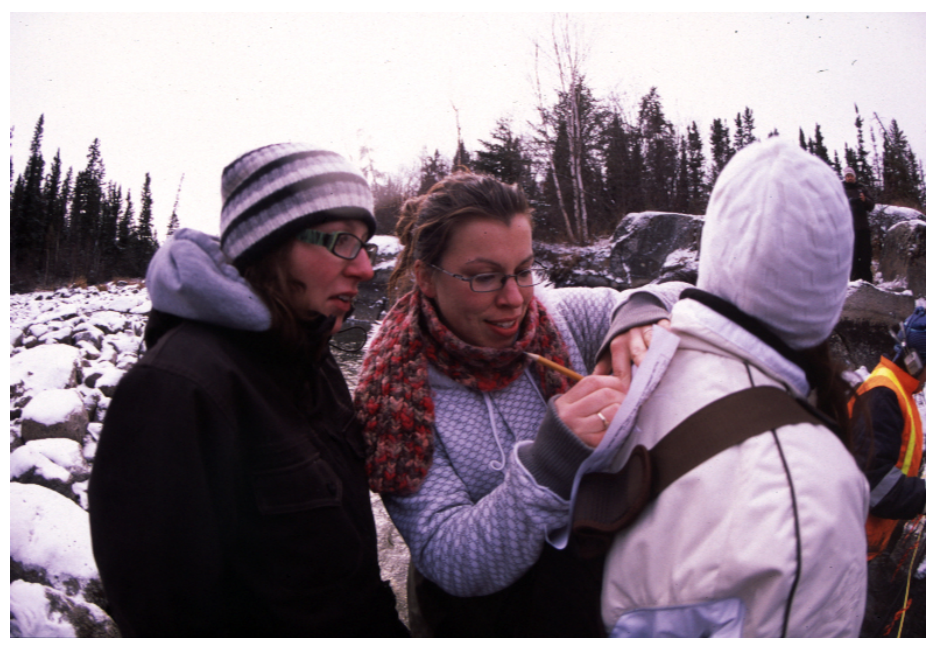

Plate 4. Students working together positively and achieving success by sharing knowledge and building consensus within the working groups. 
Students also explicated how learning in groups helped them refine traversally-adaptive skills. One participant stated "I realized my leadership capability of taking charge of a group of people" while another mentioned "others made me realize I need to ask more questions and a greater variety of questions while participating in class". In sum, "non-conventional" place-conscious delivery was cursorily shown to be an important medium creating a passionate commitment and meaningful opportunity for improved transmission and principles of increased cognitive demand suggesting students care and are contextually aware of their local northern surroundings.

Most students in the video groups mentioned a focus regarding educational and environmental advance, knowledge sharing, social responsibility and new experience; "using the camera helped me to realize". This is indicative that different lesson types are (and can be) equally effective for disseminating knowledge, but that PV played a particularly important role in creating a visually-engaging learning experience in these classes and situated exercises. Essentially, video encouraged students to discuss and share understanding with peers while in the field through a lens of place and to shift their "taken for granted" notions of that place for empirical achievement (Plate 5). Some participants stated they "developed an improved ability to network with like-minded people" and "others were really excited when I told them what I was doing".

Video additionally encouraged students to reflect relationally and associate in-class knowledge with a responsibility to dialogue passionately in the community; a positive incomprehension [111] moving them as adult participants towards place-conscious considerations necessary for sustainable futures. Some students indicated: "I am going to voice my perspective with Chief and Council regarding the environment"; "I have been thinking about the world more, not simply myself and this town-we must smarten up as I sadly found garbage and keys in this beautiful stream segment we researched-in the middle of nowhere !". Tabulating these unsolicited ("non-Likert" generated) open-ended interview responses indicated that working with a video camera and viewing learning-experience perhaps contributed to link quantitative and qualitative experiences with the wider world ${ }^{1}$.

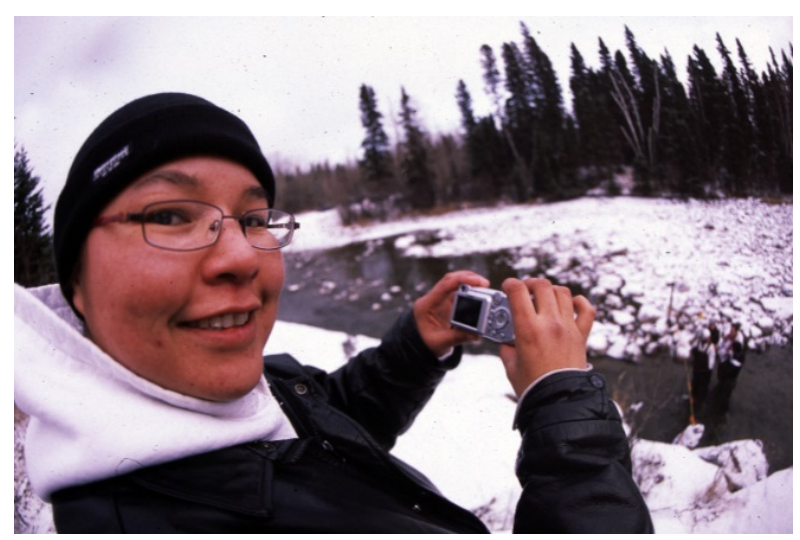

Plate 5. Student participant documenting the stream experience. 
Administratively, and from a reviewed compilation of student video archive clips of participant learning experiences, Program Directors at the UCN also realized the benefit of "non-traditional" lessons, and a need to change the traditional western "didactic" style and "metropolitanized" literary tradition of instruction that is still so prevalent. There was keen interest on the part of the Vice President of Academics and Research to have non-traditional lesson types and participatory video explored with a commitment to bring responsive innovation in existing instructional methods at UCN:

"I think that the way you are constructing curriculum will provide students with that opportunity to go beyond the scientific, go beyond the cultural, go beyond the social, to think about things from an integrated, interrelated, interdependent perspective because that is the "real" learning"

Kathryn McNaughton-Vice President Academic and Research UCN

The President of UCN further added that PV and place-responsive learning integrations could be used to complement existing lecture-based learning, in part because a variety of approaches are essential, while at the same time positing these changes were overdue and would need to incorporate-and validate-relationally responsive student experiences and learning in order to be successful-a continuum of attitudes towards the acquisition of knowledge.

"... there is a change afoot and they' re trying to hold back the dam, and the dam has to break, because the dam excludes many, and if we are not teaching and making education accessible for everyone, then we are not educators. Sadly, I think we are victims of "progress" for progress's sake-so our design must help to cultivate the spirit of asking students to examine their living and living experiences-how they are going to move forward in the future-how they are going to contribute- to understand the very place that they live."

Denise Henning_-President UCN

\section{Discussion}

Euro-didactic doggedness in lesson delivery and the capacity to eclipse situated substance in secluded northern tertiary-level literacies presents as reticent. Historically, [59] [64] [121] espoused it naïve to accept learning was restricted to classroom conventionalism. Unyielding in perspective, classic didactic prescription lingered as [39] [122] [123] forwarded suppositions that Indigenous students recognized a disconnect from local milieu. Nonetheless, Cartesian continuance and callow metaphoric presentation remained tranquil for yet another decade, failing to chronicle attentive place-conscious connection as [124] [125] [126] restated a tenacious dependence on metropolitanized lesson design. Narratively, this same continuity in traditional Western learnedness perseveres in remote teaching spaces as [37] [43] [69] [127] report monopolizing didactic ap- 
proaches in isolated and low-income areas result in poor educational outcomes.

Chronotopic (i.e., of time and place) northern Manitoba researchers report this same archetype and paradigmatic dichotomy between prescriptive didactic lecture and contextually responsive experience prevails [72] [109]. Indigenous enrollee knowledge acquisition remains oppressed at these sub-arctic latitudes resulting in mental and physical absenteeism from the University College of the North (UCN). Remarkably, locally-engaging academic opportunities for situated insight (literally out the backdoor) remain ill-linked to adult learning populaces wanting desperately to share "their" experience and connect to western Eurocentric science and contemporary environmental literacies (S. North, personal communication, January 24, 2019).

These sampled UCN student test score assessments of didactic transmissions agree with this inability to "conventionally" connect. Didactic deliveries and routine test grading schemes indicate limitations when participatory techniques and embedded opportunities were ignored. Assessed empirically and in unintegrated terms, UCN student test scores show performance as disengaged from "perceived conventional abilities" unfortunately presenting as scholastically poor; in many cases failing abjectly when learning was restricted to orthodox presentation. This documented assessment was particularly true for students participating in this northern boreal exercise who self-declared as being locally Indigenous or Aboriginal.

Though overall UCN student test performance was quite low, didactic delivery via multiple choice, sentence completion and bullet answer question types selected for improvement in only "necessary for understanding" (NFU) scores reflecting knowledge acquisition reproduced as routine memorization. Conventional didactic lesson deliveries did not recognize new place-responsive insight or what was available experientially while assimilating responsive expression and overcoming complex in-stream challenges. Such critical learning is multi-dimensional and does not typically occur in didactically-driven straightforward ways [128]. Regrettably, an over-reliance on empirical test scores generated through traditional lesson delivery and assessment appears to perpetuate the ongoing education crisis in Manitoba's north.

According to [129], decontextualized absorption of knowledge is evaluatively-fuzzy as student differences in sensory registration are compounded by embedded vernacular experience; each student perceiving incoming stimuli differently because learning and life histories, ontologies and epistemologies do not match. Unfortunately, all students are expected to perform as if incoming "enrolment-level" procurement of stultifying fact is identical. As current UCN teaching typologies remain Eurocentric in nature, there seems a niche for alternative lesson deliveries and affective assessments effective in bridging gaps between Western literacy and Indigenous expressional ends. As [130] recognized 600 kilometres to the south, financial literacy of low-income participants in Winnipeg improved when fiscal budgets were "situated" within personal 
constraint. This northern UCN research extends Buckland's assertion that non-conventional lesson deliveries encourage "qualitative" insight by presenting empirical improvement in quantitative test scores as well.

Besides affirming a locally embedded "opportunity" enhanced UCN student experience and academic performance, both didactic and non-conventional lessons were integrated with a mediating Participatory Video (PV) approach. Used with these remotely-situated adults, PV was hypothesized to facilitate training while focusing on northern student learning modalities. Successfully, PV provided a positively mediating mechanism for engaging marginalized students while enunciating their individual and collective wisdom for scholastic achievement. Moreover, the "process" of digitally capturing student interaction while in the stream would veil empirical focus of forthcoming mixed analyses ${ }^{1}$.

In accordance with [76] whose expectations are that video "help[s] other methods go even further", PV offered repeated-viewing of direct student experience embedded in traditional and non-traditional learning environs. Video proved an effective means for creating evaluator access to place-sensitive student literacy, while the methodology helped to perceive Indigenous knowledge constructs generated in context for those who participated by those who were evaluating. In essence, combinatory use of conventional and non-conventional lesson delivery using PV technology was a success. Cursorily examining unsolicited qualitative statements showed that PV in both didactic and situated "lectures" raised awareness drawing attention to vital student queries while exploring solutions to academic challenges. Statistically significant outcomes made it clear PV improved academic performance in relation to context, program type lesson delivery and remote northern learning modality. In this sense, PV facilitated empirical benefits while affirming affective student experience.

In addition to improving academic standing, UCN test findings indicated PV enhanced an "optimistic-incomprehension" and local understanding about northern freshwater sustainability. Previewed video clips of unsolicited interview themes indicated PV expedited student dialogue regarding local subject matter, problem-solving practices and context-acquired competencies. Student recordings of field exercises and video interviews frequently played a key role regarding "in-the-river" conceptualization (and calculation) of regionally-responsive freshwater availability.

Just as the work of Donald Snowden influenced subsequent generations of PV related to community development and social justice across Canada [131], the findings of my northern Manitoba study reflect outcomes of similar experiences in rural education that help to facilitate emic capacity development [132] [133] [134] [135]. References [68] [75] [82] forward similar affirmations that PV, if used within carefully negotiated relationships, has the potential to create space for participant transformation and re-imagined learning.

My use of video and "quantitative" analysis extends these recent qualitative documentations of PV as an effective mediating and learning tool. These UCN student results indicate PV empirically increased total test score "central tenden- 
cies" between five and $20 \%$ successively from didactic (D) through "didactic plus PV" (DPV), situated (S), and "situated plus PV" (SPV) lesson deliveries. Moreover, analysis of variance suggests "PV and program" interacted significantly ( $\mathrm{p}$ $=0.002)$ to increase total test scores $(19 \%)$ for NRMT-enrolled students, while increasing Total, MFP and NFU test score totals between five and $10 \%$ for students in each of the six remaining non-NRMT programs.

Importantly, participatory video interacted with "lesson" type for place-sensitive technology-mediated learning, resulting in significantly greater test scores related to long answer and calculation "question types" when both a local experience and video camera were used by the participants. Most significantly ( $\mathrm{p}=$ 0.01 ), participatory video and lesson type unified to increase Total (17\%) and NFU scores (26\%) for students engaged in "situated" (S) and "situated plus participatory video" (SPV) mediated sessions.

Conversely, NFU scores decreased when lesson deliveries were infused with $\mathrm{PV}$, perhaps indicating an information overload while attempting to cope with the deluge of new equipment, wear a pair of chest-waders, navigate benthic substrates and having to simultaneously complete a complex mathematical objective in the cold. Pragmatically, these results lead to combinatory insights related to situated theory mediated by PV for remote-based Indigenous adult learners at the UCN. Students who experienced situated and/or PV-infused lessons were more likely to acquire greater knowledge and skill test score totals compared to those who experienced didactic deliveries. Even conventional lessons used in conjunction with PV generated scholastically-increased (17\%) total test score reviews. In sum, while PV is clearly no universal remedy [136] these results beg for increased "quantitative" empirical evidence regarding non-conventional video-mediated lesson delivery.

Perhaps somewhat predictably, students who enrolled in the Natural Resources Management Technology (NRMT) program outperformed students in other non-NRMT programs even though no mention of an environmental dimension was forwarded at the initiation of research. Irrespectively, NRMT discipline-related participant test scores improved substantially (41\%) in using a non-conventional lesson delivery style (DPV, S, SPV) compared to non-NRMT related students in these same lesson delivery classes.

Gender also played a strong role in scholastic outcomes in this UCN student sample. Female students responded most positively to non-conventional lesson types as evidenced by increases in Total (24\%), MFP (30\%) and NFU (15\%) test scores. Females took advantage of PV technology more so than male counterparts displaying average test score increases of $5 \%$ across sub-score categories. Empirical increases were also apparent with question type; in that female student performance in "situated plus PV" lesson deliveries indicated a notable (20\%) improvement in long answer and calculation question types. Reference [123] similarly showed abstract competencies improved when delivered in a context relative to formal classroom environs. As these kinds of question types are sug- 
gested to facilitate performance in a wide range of jobs, traversal competencies (including high levels of persistence, attention to detail, and willingness to check for accuracy) and the requirement to think in quantifiable terms will forever be essential in order to complete job-related tasks according to [137].

Most interestingly, non-conventional lessons also enhanced Aboriginal scholastic performance with this UCN sample. Aboriginal MFP quantitative test scores increased a full grade level (12\%) when facilitated non-conventionally. Specifically, PV increased Aboriginal Total, MFP and NFU test score totals. No such improvement was exhibited by non-Aboriginal students. Effectively, the difference between non-Aboriginal and Aboriginal academic performance was reduced by PV. Moreover, differences in test scores were greater (8\%) between Aboriginal males and females than results for non-Aboriginal males and females, indicating Aboriginal males responded most strongly to PV increasing test score totals by 5\%; PV perhaps illuminating "opportunity". In short, PV in both conventional and non-conventional lesson delivery was found to be effective in enabling the academic performance of these Aboriginal students, and is thus worthy of further exploration in addressing widespread lesson-related barriers northern Indigenous students face at the UCN and likely other geographically isolated post-secondary institutions across Canada.

Chronologically, these findings support consideration of a shift for the UCN to progress from didactic teaching styles towards ones balanced with those "non-conventional" in approach. In the isolated low-income regions of northern Manitoba, there is a need for effective alternatives to didactic strategies which have been regionally criticized as being ineffective [109] [110]. In this study, situated learning methods and the strategic use of participatory video improved learning "process" and outcome (without the creation of a "product") whether lesson delivery related to knowledge acquisition, place-conscious awareness, technical skill development, or cursory examination of overt personal behavior change.

In andragogical extension, these lesson approaches infer prospective mitigation of high "failure" and dropout rates in northern Manitoba; results contributing to a positive learning experience in and outside the classroom. Non-conventional approaches captured local experiential learning in a "process" helping students reflect on issues that exist between local environment, their cultural affectivities and application of a technical undertaking - in this case - the exploration of local watershed monitoring, stream discharge calculation and freshwater sustainability. Experientially-situated learning and participatory video provided mature students with an opportunity to engage, develop skills, collect data, generate results, analyze findings, communicate "their" observations and to think critically about, and organize around, local community-based issues related to the availability of freshwater in Manitoba's remote North.

Although scholastic advance and academic relevance has yet to be verified in my PV "process" versus a "product", the alteration in approach and significance 
of "V in PV" reveals an untapped facilitative-thalweg for remote academic synergy in northern erudition and social change (J. Restoule, personal communication, February 20, 2018). Using video technology to engage marginalized participants in this isolated region visually encouraged those with "perceived" inequalities and little formal knowledge to become effective free-talk providers through chronicled and unsolicited story-telling opportunities to share and discuss their understanding of how to engage scientifically with the lotic environment.

Conducive to developing criteria for repeated viewing, video also acted as a digital repository and positively mediating mechanism for building improved scholastic understanding, heuristic clarity, model consideration disseminating ecological and educationally-sensitive data and curricular intent. Essentially, the use of digital video proved effective in both didactic and situated environments raising self, exercise and local environmental mindfulness in these UCN students.

Provincially extending [130] assertions that participatory video improves insight "qualitatively", analysis of variance of this UCN student sample suggests a place-based video technique interacted quantitatively with program type, question type, gender and northern student learning modality through three non-conventional lesson deliveries to increase scholastic test scores between five and $20 \%$. In "remote geographical essence", video provided a digital medium capable of capturing unforeseen student expression leading to unanticipated results which reflect likelihoods for improved assessment of participant priorities concerning personal transformation related to freshwater sustainability. These UCN findings press for recounted empirical evidence exploring non-conventional lesson deliveries that incorporate video-the "V in PV" and partnering "mixed" evaluative procedures.

\section{Implications}

Although aspects of this northern study bear a resemblance to insights of other research [43] [68] [105] [138], these UCN student findings address the empirical role of situated learning theory, participatory video and the idea of a "remote learning modality" in contrast to the taxonomy of culture in adult learning. These student test score results are of great educational and social importance as evaluations indicate unconventional lesson deliveries can facilitate improved academic performance. Incorporating video and axiological responsive approaches helped to perceive scholastic development by integrating and evaluating local norms and nondiscriminatory primacies within quantifiable scholarship $^{1}$.

Although this study focuses on quantitative change in empirical test scores, it is evidently important to situate and review such research within the context of fair lesson approaches so as to fully expose academic performance related to northern Indigenous learning, freshwater sustainability theories and operative provincial governance. Arguably, sole dependence on derisory quantitative test 
scores is too simplistic in evaluative nature. Complexities in northern adult learning centres require instructors working in isolated communities to purposefully develop lesson delivery methodologies. Just as important, are influential forms of complete student evaluation pointing to how local lives fit into the spaces these students occupy [39].

A first note is that controversial assumptions regarding differences in academic performance between self-declared Aboriginal and non-Aboriginal students becomes less important once one dissociates from conventionally-didactic forms of teaching and metropolitan grading routines. In so doing, a detailed dialogue that explores alternative approaches to lesson delivery and holistic student assessment is vital; concepts that resonate with [59] topoanalysis and the systematic study of sites intimate to our lives (p. 8). According to [37], this is when serviceable accomplishment in learning practice truly takes place.

Second, the aptitude to critically problem solve in local context is not the same as the ability to absorb rote scientific and technical data in a classroom. Not only is being "embedded and working cooperatively" required to advance [72] reference to place-based "ceremony", the use of generic Cartesian criteria in evaluating adult academic performance is debatably less likely to be successful in geographically inaccessible societies. To "geo-philosophically analyze" in these remote regions is the ability to navigate local relationships and incorporate vernacularly-critical insights-an evaluative "rhizomatic incorporation" of thought to assess non-linear relations between technical science and regional configurations of philosophically-conscious subjective insights [61]. Contextually, it means that northern students may not have the "words" to make these insights visible or relevant to poorly designed assessment measures.

Educational implications of these test score results are consequently serious for facilitators of those students "perceived" scholastically-at-risk and expected to meet Cartesian competencies of "matter-of-fact" technical aptitudes. Less emphasis must be placed on decontextualized fact and foreign metaphor retention. Accordingly, creatively diverse approaches to assessment are desperately required in northern Manitoba to expose historically unrecognized traits, local skill expressions and affective behaviors being offered. These UCN findings indicate variability in lesson approach affirm northern adult student knowledge procurement and traditionally un-assessed paradigms of inaptly "labeled" inabilities to meet minimum academic standard.

A third implication which needs to be drawn from this UCN student research is that some procedure for discovering what students care about is necessary before disciplinary-related enrolment and coaching commences. A mixed and integrated framework linking personal value, motivational disposition, cultural affectivity and local desirability for ecological understanding appears essential. This procedural quest has serious implications for expectations of gainful local employment with legitimate logistic possibility while residing in, and graduating from, northern remote tertiary-level settings. 
Four, feedback provided by "reviewing Elders" and involved administrators, signal that student video archives could be used for convincing various audiences that changes in northern andragogy are instructionally necessary. Targeted curricular deliveries in tertiary settings can legitimize peripheral participation related to student modalities in learning. Through similar discussions, others indirectly involved with this research proposed interesting variations for consideration. For instance, digital video archives could be used to advance assessment by: 1) rural development professionals; 2) educational psychologists; 3 ) Elders working for livelihood improvement; 4) evaluation related to local ownership, control, access and possession [OCAP] initiatives; and 5) simply to better justify appropriate educational reform in similarly isolated districts.

Finally, these documented UCN student test score achievements make it apparent that when participatory video is accompanied by principles of effective place-conscious facilitation and assessment, $\mathrm{PV}$ used simply as a process can instill a refined spirit for critical inquiry on the part of those participating. Essentially, providing the "opportunity" to share personal, social and metaphysical beliefs stimulates the ambition to excel academically. My findings corroborate and extend discoveries by [43] [68] [82] [96] [105] [138]; all of whom, as advocates of pedagogical and andragogical advance, state a situated participatory promise (and the idea of video) can provide students with a means to act critically in the cultural fabric of a provincially-constructive environmental education.

Emphatically, these situated UCN student test score findings demonstrate non-conventional and PV-mediated lesson deliveries can show isolated participants how to think empirically through metropolitanized competencies related to scientific freshwater monitoring and northern sustainability issues while cursorily exploring transversal thoughts that extend place-sensitive ceremony and transformative behaviors so desperately needed the world over. It really is up to all of us.

\section{Acknowledgements}

I am indebted to Northern Manitoba University College of the North (UCN) staff, Elders, and almost 400 students, Dr. Stephane McLachlan, Alam Ashraf, Dr. Marlene Atleo, Dr. Ian Mauro, Dr. Jean-Paul Restoule, Dr. Emdad Haque, Dr. Kathryn McNaughton, Dr. Denise Henningand Ms. Dione Peech. And from the beginning, my parents, Eleanor and Gordon Stepaniuk. I will always wish my Dad was here to see me finish. My Mom did.

\section{Conflicts of Interest}

The author declares no conflicts of interest regarding the publication of this paper.

\section{References}

[1] Nardozi, A. (2011) Perceptions of Postsecondary Education in a Northern Ontario 
Community. Doctoral Dissertation, University of Toronto, Toronto.

[2] Barry, M.N. and Dannenberg, M. (2016) Out of Pocket: The High Cost of Inadequate High Schools and High School Student Achievement on College Affordability. Education Reform Now.

[3] Gaywish, R. and Mordoch, E. (2018) Situating Intergenerational Trauma in the Educational Journey. In Education, 24, 3-23.

[4] Canadian Rural Revitalization Foundation (2015). http://www.crrf.ca/

[5] Looker, E.D. and Thiessen, V. (2003) Beyond the Digital Divide in Canadian Schools: From Access to Competency in the Use of Information Technology. Social Science Computer Review, 21, 475-490. https://doi.org/10.1177/0894439303256536

[6] Xu, D. and Jaggars, S. (2010) The Effectiveness of Distance Education across Virginia's Community Colleges: Evidence from Introductory College-Level Math and English Courses. Educational Evaluation and Policy Analysis, 33, 360-377.

https://doi.org/10.3102/0162373711413814

[7] Canadian Council on Learning (2006) The Rural-Urban Gap. http://en.copian.ca/library/research/ccl/rural_urban_gap_ed/rural_urban_gap_ed.pdf

[8] Jenkins, R. (2012) Online Classes and College Completion. http://chronicle.com/article/Online-ClassesCollege/131133

[9] Sciadas, G. (2005) Infostates across Countries and Over Time: Conceptualization, Modeling, and Measurements of the Digital Divide. Information Technology for Development, 11, 299-304. https://doi.org/10.1002/itdj.20018

[10] UCN (2015-2020) Strategic and Academic Plans. University College of the North, Manitoba.

[11] Brown, R. (2011) Community-College Students Perform Worse Online than Face to Face. http://chronicle.com/article/Community-College-Students/128281

[12] Statistics Canada (2015). http://www.statcan.gc.ca/start-debut-eng.html

[13] Davis, A. (2014) Keeping Students in Northern Manitoba Closer to Home: It Covers a Massive Territory, but This Northern School Is Designed to Make Aboriginal Students Feel Welcome. Opasquia Times. Interview with Konrad Jonasson (President).

[14] Precel, K., Eshet-Alkalai, Y. and Alberton, Y. (2009) Pedagogical and Design Aspects of a Blended Learning Course. International Review of Research in Open and Distance Learning, 10, 1-16. https://doi.org/10.19173/irrodl.v10i2.618

[15] Indian and Northern Affairs Canada [INAC] (2012) Surveys on Aboriginal Peoples. https://www.aadnc-aandc.gc.ca/eng/1321384019753/1322059098232

[16] Rey, J. and Harrison, N. (2018) Sydney as an Indigenous Place: "Goanna Walking” Brings People Together. AlterNative: An International Journal of Indigenous Peoples, 14, 81-89. https://doi.org/10.1177/1177180117751930

[17] Ballard, M. (2012) Flooding Sustainable Livelihoods of the Lake St Martin First Nation: The Need to Enhance the Role of Gender and Language in Anishinaabe Knowledge Systems. Ph.D. Thesis, The University of Manitoba, Winnipeg.

[18] Hoffman, S.M. (2004) Engineering Poverty: Colonialism and Hydroelectric Development in Northern Manitoba. University of Winnipeg, Winnipeg, Manitoba, 1-22.

[19] Pip, E. and Stepaniuk, J. (1988) The Effects of Flooding on Wild Rice (Zizania aquatica, L.). Aquatic Botany, 32, 283-290. https://doi.org/10.1016/0304-3770(88)90121-0

[20] Alderman, K., Turner, L.R. and Tong, S. (2012) Floods and Human Health: A Sys- 
tematic Review. Environment International, 47, 37-47.

https://doi.org/10.1016/j.envint.2012.06.003

[21] Waldram, J.B. (2008) Native Employment and Hydroelectric Development in Northern Manitoba. Journal of Canadian Studies, 22, 62-76.

[22] Ballard, M. and Martin, D. (2014) Lake St. Martin First Nation Community Members' Experiences of Induced Displacement: "We're Like Refugees". Refuge: Canada's Journal on Refugees, 29, 75-86.

[23] Ford, J.D., Berrang-Ford, L., King, M. and Furgal, C. (2010) Vulnerability of Aboriginal Health Systems in Canada to Climate Change. Global Environmental Change, 20, 668-680. https://doi.org/10.1016/j.gloenvcha.2010.05.003

[24] Thompson, S. (2015) Flooding of First Nations and Environmental Justice in Manitoba: Case Studies of the Impacts of the 2011 Flood and of Hydro Development in Manitoba. Manitoba Law Journal, 38.

[25] Boyd, D. (2011) No Taps, No Toilets: First Nations and the Constitutional Right to Water in Canada. McGill Law Journal, 57, 81-134. https://doi.org/10.7202/1006419ar

[26] White, J., Murphy, L. and Spence, N. (2012) Water and Indigenous Peoples: Canada's Paradox. International Indigenous Policy Journal, 3, Article 3. http://ir.lib.uwo.ca/iipj/vol3/iss3/3

[27] Kumar, A. and Farenhorst, A. (2016) Water Distribution Systems Failing. Winnipeg Free Press, Winnipeg, Canada.

http://www.winnipegfreepress.com/opinion/analysis/water-distribution-systems-fai ling-383069121.html

[28] Statistics Canada (2012) Aboriginal Peoples Survey. https://www.statcan.gc.ca/eng/survey/household/3250

[29] Office of the Auditor General of Canada (OAG) (2011) 2011 June Status Report of the Auditor General of Canada: Chapter 4-Programs for First Nations on Reserves.

http://www.oag-bvg.gc.ca/internet/english/parl_oag_201106_04_e_35372.html\#hd5f

[30] WWF-Canada (2017) Living Planet Report Canada. https://assets.wwf.ca/downloads/WEB_WWF_REPORT.pdf

[31] Bowden, M. (2011) A Brief Analysis of Bill S-11: Safe Drinking Water for First Nations Act. http://www.cba.org/cba/cle/PDF/ENV11_Bowden_Paper.pdf

[32] Rizvi, Z., Adamowski, J. and Patrick, R. (2013) First Nation Capacity in Quebec to Practice Integrated Water Resources Management. International Journal of Water. 7, 161-190. https://doi.org/10.1504/ijw.2013.054859

[33] Plummer, R., Grosbois, D., Armitage, D. and de Loe, R. (2013) An Integrative Assessment of Water Vulnerability in First Nations Communities in Southern Ontario, Canada. Global Environmental Change, 23, 749-763. https://doi.org/10.1016/j.gloenvcha.2013.03.005

[34] Cameron, E. (2012) Securing Indigenous Politics: A Critique of the Vulnerability and Adaptation Approach to the Human Dimensions of Climate Change in the Canadian Arctic. Global Environmental Change, 22, 103-114. https://doi.org/10.1016/j.gloenvcha.2011.11.004

[35] Basdeo, M. and Bharadwaj, L. (2013) Beyond Physical: Social Dimensions of the Water Crisis on Canada's First Nations and Considerations for Governance. Indigenous Policy Journal, 23, 1-14.

[36] Rafferty, A., Jimmieson, N. and Armenakis, A. (2013) Change Readiness: A Multi- 
level Review. Journal of Management, 39, 110-135.

[37] Somerville, M.J. (2010) A Place Pedagogy for "Global Contemporaneity". Educational Philosophy and Theory, 42, 326-344. https://doi.org/10.1111/j.1469-5812.2008.00423.x

[38] Hipel, K., Fang, L., Taha, B. and Bristow, M. (2013) An Introduction to the Special Issue on Tackling Challenging Water Resources Problems in Canada: A Systems Approach. Canadian Water Resources Journal, 38, 3-11. https://doi.org/10.1080/07011784.2013.773643

[39] Gruenewald, D.A. (2003) Foundations of Place: A Multidisciplinary Framework for Place-Conscious Education. American Educational Research Journal, 40, 619-654. https://doi.org/10.3102/00028312040003619

[40] Sellar, S. (2013) Equity, Markets and the Politics of Aspiration in Australian Higher Education. Discourse: Studies in the Cultural Politics of Education, 34, 245-258. https://doi.org/10.1080/01596306.2013.770250

[41] Medema, W., Adamowski, J., Orr, C., Wals, A. and Milot, N. (2015) Towards Sustainable Water Governance: Examining Water Governance Issues in Quebec through the Lens of Multi-Loop Social Learning. Canadian Water Resources Journal, 40, 373-391. https://doi.org/10.1080/07011784.2015.1088403

[42] Ison, R. and Watson, D. (2007) Illuminating the Possibilities for Social Learning in the Management of Scotland's Water. Ecology and Society, 12, 21.

http://www.ecologyandsociety.org/vol12/iss1/art21/ https://doi.org/10.5751/es-02020-120121

[43] Spillman, D. (2017) Coming Home to Place: Aboriginal Lore and Place-Responsive Pedagogy for Transformative Learning in Australian Outdoor Education. Journal of Outdoor and Environmental Education, 20, 14-24. https://doi.org/10.1007/bf03400999

[44] Ford, J., Knight, M. and Pearce, T. (2013) Assessing the "Usability" of Climate Change Research for Decision-Making: A Case Study of the Canadian International Polar Year. Global Environmental Change, 23, 1317-1326. https://doi.org/10.1016/j.gloenvcha.2013.06.001

[45] Dyball, R., Brown, V. and Keen, M. (2007) Towards Sustainability: Five Strands of Social Learning. In: Wals, A., Ed., Social Learning towards a Sustainable World: Principles, Perspectives, and Praxis, Wageningen Academic Publishers, Wageningen, 181-195. https://doi.org/10.3920/978-90-8686-594-9

[46] Battiste, M. (2009) Naturalizing Indigenous Knowledge in Eurocentric Education. Canadian Journal of Native Education, 32, 5-18.

[47] Bishop, A.J. (2002) Critical Challenges in Researching Cultural Issues in Mathematics Education. Journal of Intercultural Studies, 23, 119-131.

[48] Kitchin, R. (1999) Creating an Awareness of Others: Highlighting the Role of Space and Place. Geography, 84, 45-54.

[49] King, J.A. and Evans, K.M. (1991) Can We Achieve Outcome-Based Education? Educational Leadership, 49, 73-75.

[50] Cherubini, L. and Hodson, J. (2008) Ontario Ministry of Education Policy and Aboriginal Learners' Epistemologies: A Fundamental Disconnect. Canadian Journal of Educational Administration and Policy, No. 79.

[51] Faircloth, S.C. and Tippeconnic III, J.W. (2010) The Dropout/Graduation Crisis among American Indian and Alaska Native Students: Failure to Respond Places the Future of Native Peoples at Risk. Civil Rights Project, 40. 
[52] Sanderson, E. and Kindon, S. (2004) Progress in Participatory Development: Opening up the Possibility of Knowledge through Progressive Participation. Progress in Development Studies, 4, 114-126. https://doi.org/10.1191/1464993404ps080oa

[53] Randstrom, R. and Deur, D. (1999) Reciprocal Appropriation: Towards an Ethics of Cross Cultural Research. In: Proctor, J.D. and Smith, D.M., Eds., Geography and Ethics. Journeys in a Moral Terrain, Routledge, London, 237-250.

[54] Derrien, M.M. and Stokowski, P.A. (2014) Sense of Place as a Learning Process: Examples from the Narratives of Bosnian Immigrants in Vermont. Leisure Sciences, 36, 107-125. https://doi.org/10.1080/01490400.2013.862885

[55] Sims, L. and Falkenberg, T. (2013) Developing Competencies for Education for Sustainable Development: A Case Study of Canadian Faculties of Education. International Journal of Higher Education, 2, 1-14. https://doi.org/10.5430/ijhe.v2n4p1

[56] Manitoba Education Research Network [MERN] (2016). https://www.edu.gov.mb.ca/k12/cur/teched/resources.html

[57] UCN Faculty Handbook $(2015 / 16,2016 / 17)$ University College of the North, Manitoba.

[58] Knight, P.T. and Yorke, M. (2002) Employability through the Curriculum. Tertiary Education and Management, 8, 261-276. https://doi.org/10.1080/13583883.2002.9967084

[59] Bachelard, G. (1994) The Poetics of Space. Beacon Press, Boston, MA. (First published in 1958)

[60] Ceppi, G. and Zini, M. (1998) Children, Spaces, Relations. Metaproject for an Environment for Young Children. Domus Academy Research Center, Milan.

[61] Gough, A. (2007) Outdoor and Environmental Studies: More Challenges to Its Place in the Curriculum. Journal of Outdoor and Environmental Education, 11, 19-28. https://doi.org/10.1007/bf03400854

[62] Brown, J.S., Collins, A. and Duguid, P. (1989) Situated Cognition and the Culture of Learning. Educational Researcher, 18, 32-42. https://doi.org/10.3102/0013189x018001032

[63] Lave, J. and Wenger, E. (1991) Situated Learning: Legitimate Peripheral Participation. Cambridge University Press, Cambridge, MA.

[64] Bronfenbrenner, U. (1979) The Ecology of Human Development: Experiments by Design and Nature. Harvard University Press, Cambridge, MA.

[65] Herrington, J. and Oliver, R. (1995) Critical Characteristics of Situated Learning: Implications for the Instructional Design of Multimedia. ASCILITE 1995 Conference, University of Melbourne, Melbourne, 3-7 December 1995, 253-262.

[66] Hungerford, H.R. and Volk, T.L. (1990) Changing Learner Behavior through Environmental Education. Journal of Environmental Education, 21, 8-21. https://doi.org/10.1080/00958964.1990.10753743

[67] Rule, A.C. (2006) The Components of Authentic Learning. Journal of Authentic Learning, 3, 1-10.

[68] Chowdhury, A.H., HamblyOdame, H. and Leeuwis, C. (2014) Transforming the Roles of a Public Extension Agency to Strengthen Innovation: Lessons from the National Agricultural Extension Project in Bangladesh. The Journal of Agricultural Education and Extension, 20, 7-25. https://doi.org/10.1080/1389224x.2013.803990

[69] Scully, A. (2012) Decolonization, Reinhabitation and Reconciliation: Aboriginal and Place-Based Education. Canadian Journal of Environmental Education (CJEE), 17, 148-158. 
[70] Vincini, P. (2003) The Nature of Situated Learning. Innovations in Learning, 1-4.

[71] Papakura, M. (1986) Makereti-The Old Time Maori.

[72] Wilson, S.S. (2004) Research as Ceremony: Articulating an Indigenous Research Paradigm. Doctoral Dissertation, Monash University, Melbourne.

[73] Kimble, C., Hildreth, P.M. and Bourdon, I. (2008) Communities of Practice: Creating Learning Environments for Educators, Vol. 1. IAP, Charlotte, NC.

[74] Hansman, C.A. and Wilson, A.L. (2002) Situating Cognition: Knowledge and Power in Context. Adult Education Research Conference.

[75] Kindon, S. (2003) Participatory Video in Geographic Research: A Feminist Practice of Looking? Area, 35, 142-153. https://doi.org/10.1111/1475-4762.00236

[76] Lunch, C. (2008) Participatory Video Facilitation Course. Oxford, UK. https://insightshare.org/courses/

[77] Lewin, K. (1946) Action Research and Minority Problems. Journal of Social Issues, 2, 34-46.

[78] Leyshon, M. (2002) On Being “in the Field": Practice, Progress and Problems in Research with Young People in Rural Areas. Journal of Rural Studies, 18, 179-191. https://doi.org/10.1016/s0743-0167(01)00038-9

[79] Mattingly, D. (2001) Place, Teenagers and Representations: Lessons from a Community Theatre Project. Social \& Cultural Geography, 2, 445-459. https://doi.org/10.1080/14649360120092634

[80] McIntyre, A. (2003) Participatory Action Research and Urban Education: Reshaping the Teacher Preparation Process. Equity \& Excellence in Education, 36, 28-39. https://doi.org/10.1080/10665680303497

[81] Murthy, D. (2008) Digital Ethnography an Examination of the Use of New Technologies for Social Research. Sociology, 42, 837-855.

https://doi.org/10.1177/0038038508094565

[82] Haynes, K. and Tanner, T.M. (2015) Empowering Young People and Strengthening Resilience: Youth-Centred Participatory Video as a Tool for Climate Change Adaptation and Disaster Risk Reduction. Children's Geographies, 13, 357-371. https://doi.org/10.1080/14733285.2013.848599

[83] De Lange, N. and Mitchell, C. (2012). Building Sustainability into Work with Participatory Video. Handbook of Participatory Video, 318-330.

[84] Schwass, R. (1993) Excerpt from Interview on CBC Morningside. Environmental Studies Department, York University, Toronto, ON, 18 June 1993.

https://www.cbc.ca/archives

[85] Ferreira, G.A. (2006) Participatory Video for Policy Development in Remote Aboriginal Communities. Doctoral Dissertation, University of Guelph, Guelph, ON.

[86] Buchy, M. (2008) Insights into Participatory Video: A Handbook for the Field by Nick and Chris Lunch. Development and Change, 39, 195-196.

https://doi.org/10.1111/j.1467-7660.2008.00473_13.x

[87] Crocker, D.A. (2008) Ethics of Global Development: Agency, Capability, and Deliberative Democracy. Cambridge University Press, Cambridge.

[88] Snowden, D. (1983) Eyes See; Ears Hear. A Report to the President on Extension Service of Memorial University of Newfoundland, St. John's, Newfoundland.

[89] Evans, M. and Foster, S. (2009) Representation in Participatory Video: Some Considerations from Research with Métis in British Columbia. Journal of Canadian Studies, 43, 87-108. https://doi.org/10.3138/jcs.43.1.87 
[90] Lunch, C. (2004) Participatory Video: Rural People Document Their Knowledge and Innovations. IK Notes, The World Bank Group.

[91] Lunch, N. and Lunch, C. (2006) Insights into Participatory Video: A Handbook for the Field. InsightShare.

[92] Gilbert, B. (1992) Speaking of Fish. Exploring the Use of Popular Education in Rural Newfoundland. http://www.ryakuga.org/library/fish.html

[93] Ferreira, G.A. (2007) Pelican Case Study: Participatory Video in the Policy Making Process: The Keewaytinook-Okimakanak Case Study. University of Guelph, Guelph, Canada.

[94] Riano, P. (1994) Women in Grassroots Communication Furthering Social Change. Sage Publications, Thousand Oaks, CA.

[95] Rush, R.R. and Allen, D. (1989) Communications at the Crossroads: The Gender Gap Connection. Ablex Publishing Corporation, Norwood, NJ.

[96] Ferreira, G., Ramírez, R. and Lauzon, A. (2009) Influencing Government Decision Makers through Facilitative Communication via Community-Produced Videos: The Case of Remote Aboriginal Communities in Northwestern Ontario, Canada. Journal of Rural and Community Development, 4, 19-38.

[97] Lunch, C. (2007) The Most Significant Change: Using Participatory Video for Monitoring and Evaluation. Participatory Learning and Action, 56. International Institute for Environment and Development.

[98] Widdowson, F. and Howard, A. (2009) Disrobing the Aboriginal Industry: The Deception behind Indigenous Cultural Preservation. McGill-Queens University Press, Montreal, QC.

[99] Murphy, D., Balka, E., Poureslami, I., Leung, D., Nicol, A. and Cruz, T. (2007) Communicating Health Information: The Community Engagement Model for Video Production. Canadian Journal of Communication, 32, 383-400. https://doi.org/10.22230/cjc.2007v32n3a1966

[100] Olmos, G. (2005) Participant Authored Audiovisual Atories (PAAS): Giving the Camera Away or Giving the Camera a Way?

http://www.lse.ac.uk/collections/methodologyInstitute/pdf/QualPapers/Ramella_an d_Olmos.pdf

[101] Shaw, J. (2012) Interrogating the Gap between the Ideals and Practice Reality of Participatory Video. In: Handbook of Participatory Video, 225-241.

[102] Society for People's Education, Empowerment and Development Trust [SPEED]. (2008) Participatory Video Project.

[103] Witteveen, L. and Lie, R. (2009) Embedded Filming for Social Change: Learning about HIV/AIDS and Rural Development Professionalism. International Journal of Educational Development, 29, 80-90. https://doi.org/10.1016/j.ijedudev.2008.07.004

[104] Natural Resource Management in the Mountain Regions of Asia [NORMA] (2008) Participatory Video for Community-Led Research: Natural Resource Management in the Mountain Regions of Asia (NORMA). http://www.comminit.com/en/node/133225/306

[105] Miller, M. and Cruce, T. (2004) A 20th Century Timeline: Classroom Use of Instructional Film, Radio, and Television.

[106] Rosenstein, B. (2008) Video Use in Social Science Research and Program Evaluation. International Journal of Qualitative Methods, 1, 22-43.

[107] Goodman, S. (2003) Teaching Youth Media: A Critical Guide to Literacy, Video 
Production and Social Change. Teachers College Press, New York.

[108] Minardi, H.A. and Ritter, S. (1999) Recording Skills Practice on Videotape Can Enhance Learning: A Comparative Study between Nurse Lecturers and Nursing Students. Journal of Advanced Nursing, 29, 1318-1325. https://doi.org/10.1046/j.1365-2648.1999.01017.x

[109] Martin, N. (2014) College Fails to Make the Grade. Winnipeg Free Press, Winnipeg, Canada. http://www.winnipegfreepress.com/local/college-fails-to-make-the-grade-24665174 1.html

[110] Mercredi, O. (2009) Opasquia Times. The Pas, Manitoba.

[111] Cixous, H. and Calle-Gruber, M. (1997) Hélène Cixous, Rootprints: Memory and Life Writing. Psychology Press. https://doi.org/10.4324/9780203443590

[112] Davies, B. and Gannon, S. (2009) Pedagogical Encounters.

[113] Denscombe, M. (2009) Ground Rules for Social Research: Guidelines for Good Practice. McGraw-Hill Education, UK.

[114] Levene, H. (1960) Robust Tests for Equality of Variances. In Olkin, I., et al., Eds., Contributions to Probability and Statistics. Essays in Honor of Harold Hotelling, Vol. 2, Stanford University Press, Palo Alto, 278-292.

[115] IBM SPSS (2014) SPSS Statistical Software. www.ibm.com/products/spss-statistics

[116] Statistica (2013) Dell Statistical Software.

[117] Cortazzi, M. (1993) Narrative Analysis. Routledge.

[118] Moustakas, C. (1994) Phenomenological Research Methods. Sage Publications, Thousand Oaks, CA.

[119] Strauss, A.L. and Corbin, J.M. (1990) Basics of Qualitative Research, Vol. 15. Sage, Newbury Park, CA.

[120] Cato, M.S. and Myers, J. (2010) Education as Re-Embedding: Stroud Communiversity, Walking the Land and the Enduring Spell of the Sensuous. Sustainability, 3, 51-68. https://doi.org/10.3390/su3010051

[121] Brookfield, S. (1983) Community Adult Education: A Conceptual Analysis. Adult Education Quarterly, 33, 154-160. https://doi.org/10.1177/074171368303300303

[122] Ellsworth, E. (2005) Places of Learning: Media, Architecture, Pedagogy. Routledge.

[123] Lunce, L.M. (2006) Simulations: Bringing the Benefits of Situated Learning to the Traditional Classroom. Journal of Applied Educational Technology, 3, 37-45.

[124] Klerkx, L. (2008) Matching Demand and Supply in the Dutch Agricultural Knowledge Infrastructure: The Emergence and Embedding of New Intermediaries in an Agricultural Innovation System in Transition. Wageningen Universiteit, Wageningeng.

[125] Taguchi, H.L. (2009) Going beyond the Theory/Practice Divide in Early Childhood Education: Introducing an Intra-Active Pedagogy. Routledge, London. https://doi.org/10.4324/9780203872956

[126] Gannon, S. (2011) Difference as Ethical Encounter. Cultural Studies $\leftrightarrow$ Critical Methodologies, 11, 71-75.

[127] Manning, R.F. (2017) Place-Consciousness and Bronfenbrenner's Ecological Systems Model: A Discussion of Recurring Issues That Undermine the Teaching of Indigenous Histories in New Zealand and Australian Schools. The Australian Journal of Indigenous Education, 46, 148-159. https://doi.org/10.1017/jie.2016.31

[128] Parkes, J. and Zimmaro, D. (2016) Learning and Assessing with Multiple-Choice 
Questions in College Classrooms. Routledge.

[129] Wright, T.S. (2002) Definitions and Frameworks for Environmental Sustainability in Higher Education. International Journal of Sustainability in Higher Education, 3, 203-220. https://doi.org/10.1108/14676370210434679

[130] Buckland, J. (2010) Are Low-Income Canadians Financially Literate? Placing Financial Literacy in the Context of Personal and Structural Constraints. Adult Education Quarterly, 60, 357-376. https://doi.org/10.1177/0741713609358449

[131] Quarry, W. (1994) The Fogo Process: An Experiment in Participatory Communication. Doctoral Thesis, University of Guelph, Guelph, ON.

[132] Hedrick-Wong, Y., Kramsjo, B. and Sabri, A.A. (1997) Experiences and Challenges in Credit and Poverty Alleviation Programs in Bangladesh: The Case of Proshika. Who Needs Credit? Poverty and Finance in Bangladesh, 1-20.

[133] Chowdhury, A.H., Van Mele, P. and Hauser, M. (2011) Contribution of Farmer-to-Farmer Video to Capital Assets Building: Evidence from Bangladesh. Journal of Sustainable Agriculture, 35, 408-435.

https://doi.org/10.1080/10440046.2011.562059

[134] Mann, K. (2006) Connecting Future through Film: The Evaluate Story of Focus-Connecting Futures through a Participatory Video Project. Information about Asylum and Refugees in the UK (ICAR).

[135] Van Mele, P., Wanvoeke, J. and Zossou, E. (2010) Enhancing Rural Learning, Linkages, and Institutions: The Rice Videos in Africa. Development in Practice, 20, 414-421. https://doi.org/10.1080/09614521003710021

[136] Grudens-Schuck, N. (2001) A Qualitative Study of the Influence of Farm Leaders' Ideas on a Sustainable Agriculture Education Program. Journal of Agricultural Education, 42, 1-11.

[137] Scouller, K. (1998) The Influence of Assessment Method on Students' Learning Approaches: Multiple Choice Question Examination versus Assignment Essay. Higher Education, 35, 453-472.

[138] Witteveen, L.M., Put, M. and Leeuwis, C. (2010) Learning about Complex Multi-Stakeholder Issues: Assessing the Visual Problem Appraisal. Journal of Agricultural Education and Extension, 16, 39-54. https://doi.org/10.1080/13892240903533145 